\title{
El fomento de la igualdad de género en el trabajo a través de recursos elaborados por entidades públicas y privadas en España
}

\author{
Ana Marta Olmo-Gascón ${ }^{\star}$
}

* Doctora Cum Laude en Derecho, Universidad de Castilla-La Mancha. Máster en Dirección y Gestión de Empresas, Colegio Universitario Cardenal Gil de Albornoz. Especialista en Seguridad Social, Universidad de Castilla-La Mancha. Licenciada en Derecho, Universidad de Castilla-La Mancha. Investigadora y profesora titular, Universidad de Castilla-La Mancha.

Correo electrónico:

Marta.Olmo@uclm.es

Recibido: 25 de abril del 2013 Aprobado: 2 de septiembre del 2013

Cómo citar este artículo: Ana Marta Olmo-Gascón. El fomento de la igualdad de género en el trabajo a través de recursos elaborados por entidades públicas y privadas en España. Dxx. Diciembre 2013. At. 25

\section{Resumen}

El proceso de elaboración y gestión de los planes de igualdad en empresas y administraciones públicas es sumamente complejo, y en los últimos años diferentes entidades públicas, sindicatos más representativos y organizaciones de mujeres juristas han elaborado valiosos documentos, indicando el procedimiento y los contenidos más idóneos para garantizar el principio de igualdad de tratamiento por razón de género en el trabajo. Esta labor, que ha pasado un tanto inadvertida, es revisada en las siguientes páginas en las que, adicionalmente, se analizan los estudios procedentes de las organizaciones sindicales que revisan las medidas contenidas en la negociación colectiva y los planes de igualdad de nuestro país, destacando las que pueden considerarse como buenas prácticas para equiparar en el ámbito laboral a mujeres y hombres.

Palabras claves: medidas contra el acoso laboral sexual, medidas contra el acoso por razón de sexo, planes de acción positiva, planes de igualdad.

Promoting Gender Equality in Employment Through Resources Generated by Public and Private Entities in Spain

\begin{abstract}
The process of developing and managing equality plans in companies and government is extremely complex, and in recent years various public entities, the most representative trade unions and women's attorneys' organizations have written valuable documents, indicating the procedure and the most appropriate contents for guaranteeing the principle of equal treatment on the grounds of gender in employment. This work, which has gone somewhat unnoticed, is reviewed in the following pages, in which studies by trade unions are also analyzed to review the measures contained in collective bargaining and equality plans in our country, highlighting those that can be considered as good practice in the workplace to equate women and men.
\end{abstract}

Keywords: measures against sexual harassment, measures against gender-based harassment, affirmative action plans, plans for equality.

O FOMENTO DA IGUALDADE DE GÊNERO NO TRABALHO POR MEIO DE RECURSOS ELABORADOS POR ENTIDADES PÚBLICAS E PRIVADAS NA ESPANHA

\section{Resumo}

O processo de elaboração e gestão dos planos de igualdade em empresas e administrações públicas é sumamente complexo e, nos últimos anos, diferentes entidades públicas, sindicatos mais representativos e organizações de mulheres juristas têm elaborado valiosos documentos que indicam o procedimento e os conteúdos mais idôneos para garantir o princípio de igualdade de tratamento por razão de gênero no trabalho. Este trabalho, que passa um tanto inadvertido, é revisado nas seguintes páginas, nas quais, adicionalmente, analisamse os estudos procedentes das organizações sindicais que revisam as medidas contidas na negociação coletiva e nos planos de igualdade de nosso país, o que destaca as que podem considerar-se como boas práticas para equiparar no âmbito laboral a mulheres e homens.

Palavras-chave: medidas contra o assédio laboral sexual, medidas contra o assédio por razão de sexo, planos de ação positiva, planos de igualdade. 


\section{INTRODUCCIÓN ${ }^{1}$}

El objetivo del presente artículo es hacer un análisis acerca de los elementos que deben tener los planes de igualdad de género en el trabajo. Para conseguir este objetivo se tendrán en cuenta las experiencias y los estudios realizados por entidades públicas, sindicatos y organizaciones de mujeres.

Para alcanzar este objetivo me permito estructurar el presente artículo en los siguientes acápites: I. Introducción. II. Directrices para la elaboración de planes de igualdad o de acción positiva. III. Las condiciones laborales evaluables en un plan de igualdad. A. Acceso al empleo y contratación. B. Clasificación y promoción profesional. C. La formación ocupacional. D. Condiciones salariales. E. Ordenación del tiempo de trabajo y conciliación de la vida laboral, personal y familiar. F. Otras materias. IV. Tratamiento del acoso sexual o por razón de sexo en guías y manuales. A. La obligatoriedad de los protocolos contra el acoso con independencia del tamano de la empresa. B. La irrelevancia del consentimiento de la víctima en algunos supuestos de acoso. C. Buenas prácticas para prevenir el acoso sexual o por razón de sexo. V. Referencias.

\section{DireCtRices PARA LA ELABORACIÓN DE PLANES DE IGUALDAD O DE ACCIÓN POSITIVA}

La generalidad con que se pronuncia el art. 46 de la Ley Orgánica 3/2007, del 22 de marzo, para la igualdad efectiva entre mujeres y hombres (LOI) respecto al contenido de los planes de igualdad, ha provocado la aparición de numerosas guías o documentos de carácter técnico, que han ido precisando qué criterios deben referenciarse y las medidas que pueden adecuarse a la estructura de cada una de las empresas que pretendan articular un plan de acción positiva. Esta vaguedad, que es idónea en la medida en que opera como un listado de materias básico y mínimo que debe ser analizado dependiendo de las circunstancias concretas y de las deficiencias en materia de género de cada empresa, no aparece en cuanto al concepto de plan de igualdad que

1 Este es un artículo de reflexión derivado de diferentes estudios realizados por organizaciones sindicales y de administraciones públicas en los que se determinan cuáles pueden ser buenas prácticas laborales tendientes a generar igualdad entre hombres y mujeres. se formula con carácter funcional, explicitando las tres fases temporales que debe contener: diagnóstico de situación en la empresa, establecimiento de objetivos y verificación de resultados. ${ }^{2}$

La variedad de guías prácticas o manuales responde a la multiplicidad en la composición de las estructuras empresariales presentes en los sistemas de relaciones laborales, como manifestación, por un lado, de la libertad de empresa, y por otro, de las diversas condiciones materiales de cada actividad productiva. Por ello, encontramos guías para empresa o para administraciones públicas, y dentro de estas últimas, de carácter local o de entidades de derecho público concretas - ayuntamientos o universidades, por ejemplo- y respecto a las dirigidas a empresas, por su plantilla, guías de pequeña o mediana empresa, o bien documentos para elaborar planes de igualdad en atención al sector productivo o de actividad. También puede procederse a una clasificación por el organismo del que proceden estas pautas - nacionales, internacionales, públicos o privados. ${ }^{3}$ De toda esta diversidad se estudiarán, al hilo del contenido de la LOI, las medidas contenidas en algunos de estos instrumentos al resultar imprescindibles para emprender la ejecución de un plan de igualdad de oportunidades, analizando las pautas necesarias para evaluar, corregir y prevenir las desigualdades en cualquier organización de recursos humanos, partiendo de la premisa de la notable inestabilidad de las condiciones laborales en cualquier organización productiva, que conlleva a que la introducción de cualquier nueva condición laboral incidirá con toda probabilidad en el cumplimiento

2 Ver Instituto de la Mujer. Guía práctica para diagnosticar la igualdad de oportunidades entre mujeres y hombres en las empresas. Ministerio de Trabajo y Asuntos Sociales. 2002: El diagnóstico es el paso previo y determinante para ejecutar correctamente un plan; directrices para su elaboración.

3 Existen decenas de guías e indicadores, de entre otras, destacamos: M.J. Morales Caparros, M.J. Luna Jiménez \& A.I. Esteban Pagola. Diagnóstico de paridad en la universidad. Análisis a través de indicadores. Revista de Universidad y Sociedad del Conocimiento, vol. 7, No 2. 2010; AA.vv. Diagnóstico de la igualdad de género en el medio rural. Ministerio de Medio Ambiente y Medio Rural y Marino, Centro de Publicaciones, Madrid, 2011; Asociación Global e-Quality, Unidad de Igualdad de Género, Instituto de la Mujer de Castilla-La Mancha. Guía práctica para la incorporación del "mainstreaming" de género: ¿cómo aplicar el enfoque de género en las políticas públicas? Toledo, 2009; Fundación Mujeres, Instituto de la Mujer. Orientaciones para negociar medidas y planes de igualdad de oportunidades entre mujeres y hombres en las empresas: guías, 2008; Federación de Mujeres Progresistas-Plataforma de ong de Acción Social. Guía para la elaboración de un plan de igualdad en oNG de acción social. Madrid, Plataforma de oNG de Acción Social, 2010; A. Peláez Narváez Planes de igualdad para entidades de la discapacidad del tercer sector, Cermi, Madrid, 2010. 
del principio de igualdad de tratamiento por razón de sexo en el trabajo; ${ }^{4}$ finalmente se tratarán los mecanismos para prevenir y sancionar el acoso sexual o por razón de sexo y la articulación de estos procedimientos con los planes de igualdad.

Es importante mencionar que el llamamiento efectuado a los poderes públicos ordenando

[...] la garantía de la igualdad de trato y oportunidades en el empleo, en el acceso al empleo, incluso al trabajo por cuenta propia, en la formación profesional, en la promoción profesional, en las condiciones de trabajo, incluidas las retributivas y las de despido, y en la afiliación y participación en las organizaciones sindicales y empresariales, o en cualquier organización cuyos miembros ejerzan una profesión concreta, incluidas las prestaciones concedidas por las mismas,

efectuado en el art. 5 LOI tiene como antecedentes directos perfectamente reconocibles a la Directiva $76 / 207$ de 09.02.1976, relativa a la igualdad de trato entre hombres y mujeres en lo que se refiere al acceso al empleo, a la formación y a la promoción profesionales, así como a las condiciones de trabajo (modificada por la Directiva 2002/73/CE del Parlamento Europeo y del Consejo, del 23 de septiembre del 2002), y a la Directiva 2006/54/CE del Parlamento Europeo y del Consejo, de 05.07.2006, relativa a la aplicación del principio de igualdad de oportunidades e igualdad de trato entre hombres y mujeres en asuntos de empleo y ocupación. Este compromiso con la igualdad de tratamiento por sexo estaba exiguamente tutelado en la redacción de los arts. 4 y 17 del Estatuto de los Trabajadores, de forma que la LOI ha resultado un revulsivo que ha atendido este derecho convenientemente, y concretamente, los planes de igualdad resultan una medida perfecta para enraizar en un sistema de relaciones laborales profundamente sindicalizado en el que las disparidades por sexo siguen siendo alarmantes. ${ }^{5}$

4 Un ejemplo práctico que prevé esta revisión periódica, en el Plan de Igualdad de Danone S.A., en el que se indica que "la revisión del diagnóstico se realizará siempre que se produzca un cambio sustancial en el seno de la compañía y, al menos, cada dos años o siempre que las partes lo acuerden"; Resolución del 25 de agosto del 2009, de la Dirección General de Trabajo (вов 09.09.2009). Sin embargo, aunque la técnica es apropiada pues manifiesta la necesidad de vigilancia y revisión constante, condiciona rigurosamente este proceso, pues los cambios "no sustanciales" también pueden incidir en una distribución equitativa de derechos y obligaciones.

5 La negociación colectiva es el instrumento natural de adopción de medidas de género; aunque no es el objeto de este estudio, sí se destaca que son numerosos los análisis de las prácticas contenidas en
La LoI realiza una definición funcional de los planes de igualdad o de acción positiva; tras delimitar sucintamente su estructura - conjunto ordenado de medidas- el art. 46.1 Lor indica el objetivo de estos: "alcanzar en la empresa la igualdad de trato y de oportunidades entre mujeres y hombres y a eliminar la discriminación por razón de sexo". Seguidamente se indica secuencialmente qué fases debe contener para lograr su objetivo, pues tras un diagnóstico de situación, deben fijar los concretos objetivos de igualdad a conseguir, e incluir las estrategias y prácticas a implantar, conteniendo, finalmente, un sistema "eficaz" de seguimiento y evaluación de los objetivos fijados inicialmente. De esta forma, las cuatro etapas que necesariamente concurren y por ese orden en la elaboración de un plan, son: diagnóstico de situación; establecimiento de objetivos; determinación de estrategias y prácticas a implantar; y elaboración de un sistema eficaz de seguimiento y evaluación de los objetivos, aunque en la práctica la fijación de objetivos debe diferenciar entre los establecidos a largo y corto plazo, estos últimos progresivos y coherentes con los primeros, y el diseño de acciones concretas que aseguren la coherencia entre objetivos y acciones. Para garantizar la funcionalidad de las medidas, previamente será preciso analizar el objetivo, los sujetos a los que se dirige, el sujeto responsable de su aplicación, la metodología de implantación y los recursos y sistemas de verificación de su cumplimiento, recogiendo dicha información en fichas individuales, en las que se debe hacer constar el plazo de seguimiento en su cumplimiento y el procedimiento de evaluación de los resultados. Estas fases deben volcarse en un calendario de actuaciones que, una vez cumplido, nos indicará los puntos a corregir en la empresa y las medidas adecuadas para ello. ${ }^{6}$

los convenios colectivos. Los que se reseñan a continuación son de obligatoria consulta, pues ofrecen dos panorámicas reveladoras de la positiva evolución convencional en la materia: AA.vv. Los planes de igualdad entre mujeres y hombres en la negociación colectiva. Instituto de la Mujer, Ministerio de Igualdad, Madrid, 2009, y AA.vv. Negociando la igualdad en las empresas: estado de la cuestión y estrategias para la implementación de una política de igualdad de género, O. Molina Hermosilla (Dir.), Comares, Granada, 2012.

6 Modelo propuesto en el Manual para elaborar un Plan de Igualdad en la empresa. Aspectos básicos. Ministerio de Trabajo y Asuntos Sociales, Secretaría General de Políticas de Igualdad, Instituto de la Mujer, págs. 10 y ss. Una guía similar: Manual para elaborar un plan de igualdad en la empresa. Federación de Servicios Públicos de UGT de Madrid. Indicaciones metodológicas para efectuar el diagnóstico: Gestión práctica de Planes de Igualdad. O. Molina Hermosilla, (ed.). Bomarzo, Albacete, 2009. 
Por otro lado se indica un listado de materias básicas que pueden formar parte de un plan de igualdad; en primer lugar el art. 46.2 LOI establece este listado con carácter orientativo indicando que el plan puede contener estas "u otras" materias, y además se explica, generando cierta confusión, que estas materias podrán incluirse o no "para la consecución de los objetivos fijados", debiendo, en nuestra opinión, aparecer obligatoriamente al menos en la primera fase de diagnóstico, pues difícilmente trazaremos un análisis realista de la situación de la empresa si omitimos condiciones laborales básicas. Las materias que se enuncian son acceso al empleo; clasificación profesional; promoción y formación; retribuciones; ordenación del tiempo de trabajo; conciliación laboral, personal y familiar; y prevención del acoso sexual y del acoso por razón de género. Efectivamente la obligatoriedad de testar el cumplimiento del principio de igualdad de estas y cualesquiera otras condiciones laborales no enunciadas pero específicas o relevantes en el espacio productivo de que se trate, se torna en la obligación de establecer objetivos sólo cuando se detecte un incumplimiento en una materia concreta, pues es posible que ya se garantice un estricto respeto a la igualdad en determinadas materias, situación que previsiblemente se irá produciendo con más habitualidad si la empresa ya ha instaurado y revisado planes de igualdad. De igual modo, los criterios seleccionados para efectuar un primer diagnóstico podrán repetirse u obviarse en los sucesivos, cuando en la evaluación de los resultados de las medidas propuestas se concluya que ya se han alcanzado. ${ }^{7}$ Como paso previo a la realización del diagnóstico es preciso recabar los

7 Un buen ejemplo de los datos necesarios para efectuar el diagnóstico en el Convenio Colectivo de la Compañía Española de Petróleos, S.A. (Cepsa), en el que se precisa que debe disponerse de los "datos desagregados por sexo de: a) Distribución de la plantilla en relación con la edad, antigüedad, departamento, nivel jerárquico, grupo profesional y nivel de formación académica; b) Distribución de la plantilla en relación con el tipo de contrato; c) Distribución de la plantilla en relación con el grupo profesional y nivel salarial de Convenio; d) Distribución de la plantilla en relación con ordenación de la jornada, horas anuales de trabajo, régimen de turnos y medidas de conciliación de la vida familiar y laboral; e) Ingresos y ceses producidos en los últimos cinco años especificando grupo profesional, edad y tipo de contrato; f) Niveles de absentismo de los años 2006 y 2007, especificando grupos profesionales; g) Horas de formación de los años 2006 y 2007 y tipo de acciones formativas; h) Salarios medios por sexo, incluyendo todos los conceptos salariales. Del personal excluido de Convenio se facilitarán los índices salariales que permitan hacer un diagnóstico de salarios por sexo". En: C. Bravo \& R. Gómez. Buenas prácticas en la negociación de los planes de igualdad. Secretaría Confederal de la Mujer ccoo, Madrid, 2010, pág. 25. Ver directrices prácticas para realizar la fase de diagnóstico en: Federación de Servicios a la Ciudadanía de ccoo. Aclarando algunas dudas sobre planes de igualdad. págs. 43-47, Madrid, 2011. datos — para su posterior análisis—, de determinadas condiciones de la prestación laboral; una vez constatada la situación discriminatoria a corregir, el procedimiento exige la fijación de objetivos y su diseño de la temporización, señalando la persona u órgano de gestión responsable de su implantación y la partida económica destinada en su caso. Finalmente debe procederse a una evaluación de los resultados, en la que los no alcanzados o conseguidos parcialmente deberán ser objeto de un nuevo proceso de diseño e implantación.

Desde el ámbito jurídico laboral resulta especialmente interesante analizar las condiciones laborales que deben ser evaluadas, explorando en qué medida pueden resultar lesivas al derecho a la igualdad, y conjuntamente los mecanismos oportunos a implementar, estudio en el que, además, haremos referencia a algunos ejemplos incluidos en la negociación colectiva.

\section{LAS CONDICIONES LABORALES EVALUABLES EN UN PLAN DE IGUALDAD}

\section{A. Acceso al empleo y contratación}

Que la tasa de desempleo afecte en España mayoritariamente a la mujer es sin duda consecuencia de la confluencia de factores de diversa índole; a pesar de que la tardía incorporación de la mujer al mercado laboral en nuestro país parece una rémora superada, determinados roles sociales siguen presentes incluso entre una parte de la población joven, presuponiendo que las tareas de atención al núcleo familiar deben ser desempeñas preferentemente por la mujer. Resulta paradójico que esta inferior tasa de ocupación no es provocada por el nivel de formación en la que precisamente la mujer tiene un porcentaje cuantitativo y cualitativamente superior al de los hombres; ${ }^{8}$ mantener que la educación sería la solución a este estereotipo debe matizarse en unas décadas en las que en España hay un índice de titulados(a)s universitarios notable, de for-

\footnotetext{
8 En el 2010, el 55\% del conjunto de estudiantes universitarios de la Unión Europea eran mujeres. Las diferencias entre sexos están marcadas por la evolución del alumnado universitario, según las áreas de conocimiento, la presencia de mujeres en matemáticas, ciencias e informática es del $41 \%$ descendiendo al 26\% en el ámbito de las ingenierías. Esta segmentación de la población universitaria tendrá su reflejo en la inserción en el mercado laboral. AA.vv. Crisis y discriminación salarial de género. Secretaría Confederal de la Mujer ccoo, pág. 18. Madrid, 2012.
} 
ma que cabe precisar que efectivamente la eliminación de patrones erróneos debe hacerse por la educación, pero por una educación con perspectiva de género que desde la infancia identifique y corrija los estereotipos discriminatorios presentes en la sociedad. ${ }^{9}$ Otro problema típico es la infravaloración del trabajo femenino, pues, cumpliendo las condiciones de titulación requeridas para ocupar puestos de mayor rango, frecuentemente se contrata a la candidata femenina para ocupar puestos de escasa cualificación, lo que evidentemente conlleva una precariedad salarial muy habitual. El plan de igualdad debe componer el conflicto existente entre la libertad de contratación de que dispone el empresario, con el cumplimiento del principio de igualdad de tratamiento (art. 4 del Estatuto de los Trabajadores) evitando que bajo la apariencia de un uso regular de su derecho, se lesione el de rango fundamental de las candidatas femeninas. ${ }^{10}$

Para garantizar que la selección de trabajadores se efectúa respetando criterios de igualdad tanto en la selección para ocupar vacantes, como en la promoción profesional, es común que los documentos técnicos señalen diferentes mecanismos en los que es preciso adoptar usos adecuados; concretamente, respecto a las ofertas de empleo, los tests psicotécnicos y las pruebas profesionales o entrevistas, es recomendable

[...] que en el anuncio correspondiente de la oferta de empleo el puesto sea nombrado en femenino y masculino, además de utilizar vías de comunicación que lleguen tanto a hombres como a mujeres. Las preguntas en las entrevistas se ceñirán a las que guarden relación con el puesto de trabajo, y sería conveniente formar al equipo de selección en técnicas de entrevista desde la perspectiva de igualdad de oportunidades. También se puede garantizar que exista representación femenina en los equipos de selección de las empresas. ${ }^{11}$

9 En esta materia, consultar:M. Elosegui Itxaso. Educaren la corresponsabilidad entre mujeres y hombres: la igualdad necesaria. Revista General de Derecho Canónico y Derecho Eclesiástico del Estado, № 20, 2009.

10 Supuesto que en la mayoría de las ocasiones es difícil de probar. Cfr. G. Fabregat Monfort. La discriminación de género en el acceso al mercado de trabajo. La posibilidad de una nueva tutela a la luz de la Ley Orgánica $3 / 2007$, del 22 de marzo, para la igualdad efectiva de mujeres y hombres. TLB, Valencia, 2008, y de la misma autora, Los planes de igualdad como obligación empresarial, Bomarzo, Albacete, 2009, pág. 55.

11 C. Bravo \& R. Gómez, Op. cit., pág. 39. Directrices a seguir en el concreto proceso de ingreso en la empresa: Emakunde/Instituto Vasco de la Mujer. Guía para un proceso de selección no discriminatorio. 2004, o Ministerio de Trabajo y Asuntos Sociales, Instituto de la Mujer. Guía para una selección de personal no sexista.
De esta forma, es preciso utilizar criterios objetivos para la selección - tales como la formación-y evaluar en la fase de diagnóstico qué sujetos intervienen en la definición de los perfiles de los puestos a cubrir, qué departamento o personal se encarga de diseñar el proceso, y quién o quiénes toman la decisión final de incorporar al candidato(a). ${ }^{12}$ En cuanto a la intervención de la representación de los trabajadores en esta fase de reclutamiento de personal, esta es muy recomendable en dos momentos concretos: uno, en el diseño del sistema de selección, procurando que se utilicen criterios equitativos, y dos, en la baremación de estos, certificando que se cumplen. Otra posibilidad procura un sistema de participación sindical más débil en el que la representación sólo es informada de las fases, el contenido y los resultados del proceso de contratación. ${ }^{13}$ Finalmente, como mecanismo preventivo para evitar una plantilla masculinizada o segmentada por género, el plan deberá incluir la revisión periódica del sexo de la plantilla en todos los puestos y categorías profesionales.

Concretamente uno de los mejores procedimientos para corregir la deficiente situación laboral femenina en el acceso al empleo es la conocida como acción positiva, reconocida en derecho europeo en el art. 157 del Tratado de Funcionamiento de la Unión Europea del 2009, permitiendo a los Estados miembros arbitrar "medidas que ofrezcan ventajas concretas destinadas a facilitar al sexo menos representado el ejercicio de actividades profesionales o a evitar o compensar desventajas en sus carreras profesionales", acciones que debe ser razonables y proporcionadas (art. 11.1 LOI) en la medida en que operan a favor del colectivo desfavorecido en un momento o situación concreta y que quedan afianzadas legalmente en el art. 17 del Estatuto de los Trabajadores (ЕT). Que la acción positiva suponga una ruptura del universal principio de igualdad de tratamiento, además de superar el juicio de racionabilidad, queda justificado por su eventualidad, pues si actualmente deben operar a favor de las trabajadoras que, en efecto son frecuentemente discriminadas, en el momento en que se alcance una igualdad efectiva entre trabajadores y trabajadoras deberían desaparecer, y sólo retomarse si la igualdad de derechos se in-

12 Manual para elaborar un Plan de Igualdad en la empresa. Aspectos básicos. Op. cit., págs. 51-53.

13 Intervención presente en nuestra negociación colectiva incluso antes de la promulgación de la LOI en el 2007; ver numerosos ejemplos en: J.M. Serrano García. Participación y planes de igualdad en la Ley Orgánica de Igualdad efectiva entre mujeres y hombres, Albacete, Bomarzo, 2007 págs. 110-111. 
clina de nuevo a favor de un grupo exclusivamente por razón de género. ${ }^{14}$ En la práctica es común que tanto en guías para la elaboración de planes de igualdad, como en los propios planes, se incluyan acciones positivas en contratación utilizando como criterio para su activación que exista una infra representación de trabajadoras en el área o puesto de trabajo que se pretenda cubrir, y condicionando su operatividad a la "idoneidad" de la candidata para las tareas a desempeñar; el margen de interpretación subjetiva de esta condicionalidad aconseja prescindir de ella y adoptar fórmulas más neutras como el mérito y la capacidad. ${ }^{15}$ También se utiliza la reserva de un porcentaje de las plazas vacantes para mujeres como medida temporal hasta que ellas sean seleccionadas de una manera normalizada. ${ }^{16}$

Uno de los mayores problemas del empleo femenino en España es su contratación a tiempo parcial, frecuentemente además con carácter temporal. Advertido que el tiempo parcial no es estrictamente una modalidad contractual - aunque sí formalmente-, sino una forma de distribución de la jornada, se trata de una cuestión que se incluye en guías y en la práctica convencional en el apartado de contratación. Las sucesivas reformas legales que ha sufrido el régimen de

14 A.M. Olmo Gascón. Igualdad por razón de sexo. Diccionario Internacional de Derecho del Trabajo. Valencia, тLв (en prensa). Reflexionando sobre la naturaleza de la acción positiva y el derecho a la igualdad como medio o como resultado, ver M. Vittoria Ballestrero. Igualdad y acción positiva. Problemas y argumentos de una discusión infinita. DoxA, Cuadernos de Filosofía del Derecho, No 29, 2006. Sobre la diferencia entre acciones positivas y discriminaciones inversas, vid.: M. Elosegui Itxaso. La Ley Orgánica de igualdad efectiva entre mujeres y hombres: las acciones positivas para la igualdad laboral entre mujeres y hombres. Aequalitas: Revista jurídica de igualdad de oportunidades entre mujeres y hombres, № 20, 2007, págs. 11 y ss. Estrictamente en el ámbito laboral, ver Pérez del Río, M.T. Principio de no discriminación y acción positiva. Comentario a la Parte III del Plan de Igualdad de Oportunidad para la Mujer 1988-1990. Documentación Laboral, № 25, págs. 55-98, 1988.

15 Federación Agroalimentaria, Secretaría Mujer e Internacional ccoo. Planes de igualdad en el sector agroalimentario, pág. 18, 2009; Plan de Igualdad de Vossloh España, S.A. (2009-2012), señalando que las acciones positivas podrán planificarse para "las condiciones de contratación, salariales, formación y condiciones de trabajo en general, de modo que en igualdad de condiciones de idoneidad tendrán preferencia las personas de género menos representado en el grupo profesional de que se trate"; C. Bravog \& R. Gómez, Op. cit., págs. 37 y 41. En cambio, recogiendo la fórmula "Promover que a igual mérito y capacidad, se contemple positivamente el acceso de personas cuyo género no esté debidamente representado en una categoría o función determinada”, en Plan de Igualdad de la empresa Compañía Española de Petróleos, S.A. (Cepsa), Resolución del 23 de agosto del 2011, de la Dirección General de Trabajo, por la que se registra y publica el Plan de Igualdad de Compañía Española de Petróleos, S.A. (BOE 05.09.2011), pág. 96079.

16 Cámara Oficial de Comercio e Industria de Madrid. Guía para la implantación de un plan de igualdad en las pymes al amparo de la nueva ley de igualdad 2007. pág. 17, 2007. tiempo parcial han flexibilizado tanto su utilización por parte del empresario que prácticamente avocan al trabajador a una precariedad laboral - y por ende económica - injustificable. Aparte de la percepción de un salario insuficiente en la mayoría de las ocasiones, el problema añadido es la incompatibilidad de varias actividades a tiempo parcial precisamente por la libre disposición sobre el horario de que dispone el empresario. Que el tiempo parcial cumpliera la función de permitir compatibilizar un tiempo de trabajo limitado con actividades de atención al núcleo familiar exigiría unas condiciones en nuestro mercado laboral que están lejos de cumplirse: una retribución mayor de la hora trabajada a tiempo parcial — sea ordinaria, extraordinaria o complementaria - y la imposibilidad de compensarse por tiempo equivalente de descanso, y adicionalmente, una voluntariedad real en la prestación bajo esta modalidad que permitiera a la trabajadora optar a un tiempo completo de trabajo cuando sus necesidades vitales lo exigieran. Tal y como revelan los estudios en la materia, a parte de que el porcentaje de mujeres que trabajan a tiempo parcial es cuatro veces superior al de los hombres en la UE (un 32\% frente a un 8\%), el 24\% de ellas especifican que es debido a no encontrar empleo a tiempo completo. En nuestro caso el escenario es mucho peor pues el $48 \%$ de las mujeres que trabajan a tiempo parcial en España alegan no encontrar empleo a tiempo completo, mientras que el $27 \%$ explica que es para atender el cuidado de niños y las responsabilidades familiares. Esta situación afecta especialmente a la mano de obra joven, pues mientras que en la Unión Europea el $22 \%$ de los hombres entre 15 y 24 años tiene un contrato a tiempo parcial, en el caso de las mujeres este porcentaje asciende al $37 \% .{ }^{17}$

La contratación a tiempo parcial no sólo ocasiona un desplome de las condiciones salariales de la trabajadora durante su vida laboral activa, en el caso español el régimen de jubilación contributiva también la discrimina económicamente. Un pronunciamiento ejemplar que exige la modificación de la normativa española Sentencia del Tribunal de Justicia (Sala Octava) del 22 de noviembre del 2012, asunto C-385/11, Isabel Elbal Moreno/INss, TGSs- afirma que nuestro régimen actual de jubilación

[...] exige a los trabajadores a tiempo parcial, en su inmensa mayoría mujeres, en comparación con los tra-

17 Datos procedentes de AA.vv. Crisis y discriminación salarial de género. Op. cit. págs. 16-17. 
bajadores a tiempo completo, un periodo de cotización proporcionalmente mayor para acceder, en su caso, a una pensión de jubilación contributiva en cuantía proporcionalmente reducida a la parcialidad de su jornada (No 39 sentencia).

De este modo se está vulnerando el artículo 4 de la Directiva 79/7/CEE del Consejo, de 19 de diciembre de 1978, relativa a la aplicación progresiva del principio de igualdad de trato entre hombres y mujeres en materia de seguridad social. El Tribunal rechaza las alegaciones del Inss y del Gobierno español en las que aducen que

[...] la exigencia de determinados periodos de cotización previos para poder acceder a determinadas prestaciones constituye la expresión de un objetivo general de política social perseguido por el legislador nacional, puesto que esta obligación es esencial en el marco de un sistema de seguridad social de tipo contributivo, en particular, para garantizar el equilibrio financiero del sistema ( $\mathrm{No} 33$ sentencia),

afirmando que la discriminación económica no es necesaria para salvaguardar el citado equilibrio financiero. Además, resulta especialmente apropiado el reconocimiento que hace el Tribunal de que se estima estadísticamente probado, que una normativa como la denunciada, afecta a una proporción mucho mayor de mujeres que de hombres, por cuanto en España al menos el $80 \%$ de los trabajadores a tiempo parcial son mujeres ( $N^{\circ} 31$ sentencia).

Los fenómenos de externalización productiva constituyen otro elemento que precariza notablemente la mano de obra femenina; la utilización de mano de obra ajena procedente de contratas o subcontratas, y empresas de trabajo temporal, es frecuentemente referenciada en planes de acción positiva o convenios colectivos con contenido en materia de género. Habitualmente se utilizan fórmulas genéricas tendientes a que las empresas que suministran personal, conozcan y respeten los mecanismos implantados en la empresa para el fomento de la paridad de tratamiento, insuficientes en la medida en que han quedado superados por las disposiciones normativas. ${ }^{18}$ Esta materia, en la que la autonomía de las partes en la negociación de me-

18 Por ejemplo: "Garantizar que las empresas de trabajo temporal y contratas que dan servicio a la compañía, conocen nuestros compromisos en materia de igualdad, al objeto de evitar posibles malos usos derivados de la existencia de culturas empresariales diversas". Plan de Igualdad de la empresa Compañía Española de Petróleos, S.A. (Cepsa), Resolución del 23 de agosto del 2011, cit., pág. 96079. didas juega un papel nuclear, es idónea para introducir mecanismos funcionales que se adapten a esta colaboración de empresas; el plan de acciones positivas puede - y sería lo oportuno- establecer que las trabajadoras de empresas externas deben beneficiarse de todas las medidas previstas en el plan de igualdad que materialmente se les puedan aplicar mientras desempeñen sus funciones en la empresa usuaria; de esta forma, se daría cumplimiento a lo dispuesto en el art. 11.1 de la Ley 14/1994, de empresas de trabajo temporal, que establece que

los trabajadores contratados para ser cedidos tendrán derecho a que se les apliquen las mismas disposiciones que a los trabajadores de la empresa usuaria en materia de protección de las mujeres embarazadas y en periodo de lactancia, y de los menores, así como a la igualdad de trato entre hombres y mujeres y a la aplicación de las mismas disposiciones adoptadas con vistas a combatir las discriminaciones basadas en el sexo, la raza o el origen étnico, la religión o las creencias, la discapacidad, la edad o la orientación sexual. ${ }^{19}$

Esta extensión del ámbito aplicativo al personal externo perfectamente justificado por el aprovechamiento del empresario principal sobre la prestación de una mano de obra ajena, es especialmente recomendable en el caso de los protocolos contra el acoso sexual, puesto que los riesgos profesionales —en este caso intimidación sexual o por sexo- los provoca el entorno empresarial al que se desplaza la trabajadora; judicialmente, el art. 177.4 de la Ley 36/2011, de 10 de octubre, reguladora de la jurisdicción social, permite demandar por acoso a empresarios interpuestos en la medida en que se puede recurrir a la jurisdicción social "contra cualquier otro sujeto que resulte responsable, con independencia del tipo de vínculo que le una al empresario". ${ }^{20}$ En estos casos, lo lógico sería una regulación legal que imponga la aplicación del protocolo contra el acoso laboral o por sexo existente en la empresa contratista/ subcontratista o usuaria a la que pertenece el empleado que provoca el hostigamiento, pues al fin y al cabo es la que dispone de la facultad de sanción laboral. De

19 Marco de protección legal ya reclamado y propuesto con anterioridad a la reforma del precepto para empresas de trabajo temporal - y para contratas y subcontratas (actualmente huérfanas de tutela legal)-, en: A.M. Olmo Gascón. La tutela frente al acoso sexista en el trabajo. Violencia contra las mujeres. Un enfoque jurídico. Septem Ediciones, Oviedo, 2011, págs. 205-208.

20 G. Fabregat Monfort. La obligación empresarial de tutela frente al acoso laboral en la empresa. pág. 112, Bomarzo, Albacete, 2011. 
igual forma, si el acoso lo provoca el empleado enviado en misión o desplazado a una subcontrata, contra personal de la empresa con la que comparte el espacio de trabajo, el protocolo a activar - por denuncia del trabajador(a) acosado aunque sea ajeno a la plantillaes el de la empresa a la que pertenece el autor de la conducta denunciada, protocolo o procedimiento contra el acoso sexual de existencia obligatoria, ${ }^{21}$ tal y como se analizará al tratar esta cuestión.

\section{B. Clasificación y promoción profesional}

El acto de la clasificación profesional es el determinante del resto de las condiciones laborales que va a disfrutar la empleada; el salario, la jornada, las posibilidades de promoción, los riesgos profesionales y hasta las condiciones económicas de extinción laboral o la jubilación dependerán del puesto de trabajo que se ocupe en la empresa. Las guías contienen un variado catálogo de medidas en la materia, tales como utilizar el sistema nacional de clasificaciones profesionales para identificar los puestos de trabajo presentes en la empresa, o la elaboración de la clasificación profesional con base en pautas neutras como la formación, la iniciativa, la autonomía, la complejidad de la actividad, la responsabilidad o el liderazgo preciso para su desempeño. Un elemento básico e inexcusable para evitar la discriminación en este ámbito es la eliminación del identificador sexual en la definición de los puestos de trabajo, práctica aún frecuente en algunas ofertas de empleo. ${ }^{22}$

En esta materia de nuevo se detecta un problema del sistema de relaciones laborales español; el sector productivo con mayor peso es el de los servicios, en el que la mano de obra que se precisa es de nula o escasa cualificación, y que está atendido mayoritariamente por trabajadoras, frente a sectores como el industrial, en el que las empresas precisan un mayor porcentaje de técnicos cualificados (diplomadas, licenciadas o graduadas, o formación profesional de segundo ciclo). Precisamente los sectores productivos en los que se requiere mano de obra con mayor titulación, están completamente masculinizados (por ejemplo, el

\footnotetext{
21 A.M. Olmo Gascón. Op. cit., págs. 201-203.

22 Afortunadamente la tendencia de la negociación colectiva es la eliminación de este sexismo en la clasificación profesional, con alguna desafortunada excepción; M.J. Dilla Catala. La clasificación profesional y la retribución salarial. Análisis de medidas y planes de igualdad en la negociación colectiva. pág. 35, Observatorio de Medidas y Planes de Igualdad en la Negociación Colectiva, Comisión Ejecutiva Confederal de UGT, 2011
}

sector industrial en el que el salario medio es mayor en comparación con el sector servicios) y además, es donde se advierte una mayor brecha salarial entre salarios medios de hombres y mujeres en comparación con otros sectores. ${ }^{23}$ En la práctica, el fomento de la igualdad en la clasificación profesional prevé una batería de medidas muy adecuadas; el diseño de planes de carrera específicos para determinadas trabajadoras, la promoción de acciones positivas en las actividades de formación reservando una cuota femenina, el fomento de las habilidades directivas de las mujeres, o el aumento del control de cada persona sobre su puesto de trabajo, repercuten no sólo en una clasificación no sexista, pues además generan una mayor satisfacción del trabajador(a) en su vida profesional y personal. ${ }^{24}$ Pero como paso previo a la adopción de medidas concretas, es preciso que la elaboración de la clasificación profesional no reproduzca la segregación sexual existente en el mercado de trabajo y elimine cualquier componente discriminatorio en las funciones asignadas a los grupos o niveles profesionales, ${ }^{25}$ de igual forma que todo plan debería contener la formación interna en materia de igualdad de oportunidades, especialmente dirigida a los equipos de dirección y gestión de la empresa, que al fin y al cabo serán los responsables de garantizar el res-

\footnotetext{
23 AA.vv. Crisis y discriminación salarial de género. Op. cit. págs. 18, 32-33 y $35-38$.

24 Guía para la implantación de un plan de igualdad en las pymes al amparo de la nueva ley de igualdad 2007, cit., pág. 19.

25 J.C. García Quiñones. La formación profesional, los sistemas de promoción y los sistemas de clasificación profesional. Análisis de medidas y planes de igualdad en la negociación colectiva, cit., pág. 133; el autor tras el análisis de una generosa muestra de planes de igualdad adoptados en los últimos años en nuestro país, indica que las medidas más oportunas en esta materia deben centrarse en la "compatibilización entre la formación y la asunción de responsabilidades familiares, además de la anunciada compensación económica cuando los trabajadores o trabajadoras con hijos deban de soportar gastos extraordinarios por ejemplo, de guardería para el seguimiento de la formación ofrecida, resultan interesantes potencialmente otras cláusulas de igualdad en previsión de la organización de los cursos de formación durante la jornada laboral; o aquellas que otorguen prioridad para recibir la formación durante dicha jornada a los trabajadores y trabajadoras con responsabilidades familiares, como expresión de conciliación de la vida profesional y familiar; estableciendo criterios de excepcionalidad respecto de los trabajadores con cargas familiares cuando los cursos de formación impliquen residir fuera del hogar familiar; otorgando prioridad en la elección del horario para la realización de los cursos de formación respecto de aquellos trabajadores con responsabilidades familiares; o evitando que las ausencias del trabajador o trabajadora para el cuidado de hijos u otros familiares repercuta negativamente en su situación profesional en la empresa, manteniendo siempre su derecho a la formación para no perjudicar su situación profesional, por ejemplo, en situaciones de permiso de maternidad, paternidad o excedencia voluntaria por cuidado de hijos o familiares", pág. 124
} 
peto a la paridad sexual, y que en el caso de la plantilla es frecuente que se realice mediante charlas de sensibilización. ${ }^{26}$ La medida, por su obviedad, puede parecer innecesaria dado que se trata de un derecho a la igualdad universalmente conocido; sin embargo, verbalizar el derecho y su contenido revela aspectos y manifestaciones de este habitualmente desconocidos por la plantilla que, una vez razonados, se aceptan y cumplen con más normalidad.

La clasificación profesional es una materia directamente relacionada con la promoción en la empresa; el puesto que se ocupa condiciona la futura carrera profesional de manera que es corriente que tanto en manuales de elaboración de planes de acción positiva como en los propios planes estas materias se traten conjuntamente. El proceso de ascenso en la empresa puede venir reglado en la negociación colectiva, o por acuerdo colectivo en su defecto; en ambos casos es preciso incluir en el plan pautas que no perjudiquen a las candidatas femeninas pues, tal y como ordena el art. 24.2 ET:

Los ascensos y la promoción profesional en la empresa se ajustarán a criterios y sistemas que tengan como objetivo garantizar la ausencia de discriminación directa o indirecta entre mujeres y hombres, pudiendo establecerse medidas de acción positiva dirigidas a eliminar o compensar situaciones de discriminación.

Los ejemplos propuestos incluyen el establecimiento de criterios objetivos y medibles para poder acceder a una promoción o ascenso; la comunicación abierta y pública en la empresa de la disponibilidad del puesto y de los criterios para acceder a esa promoción; el establecimiento de programas de "monitorizaje" designando un tutor(a) a la trabajadora con potencial para ocupar puestos de mayor categoría-, o garantizar la presencia sindical y femenina formada en género en los órganos responsables de decidir la promoción..$^{27}$ Una de las medidas más adecuadas, siempre que el puesto de trabajo lo permita, es la elección del trabajo por objetivos como mecanismo para evaluar a los/ las candidatos que opten al ascenso, además de ser un buen sistema para determinar partidas salariales. Este

26 Manual para elaborar un Plan de Igualdad en la empresa. Aspectos básicos, Op. cit., págs. 86-87. Conviene que este proceso de información y sensibilización también se realice con los representantes de personal; Secretaría de Igualdad de UGT-Madrid. Guía para la elaboración de planes de igualdad en las empresas, pág. 36.

27 Guía para la implantación de un plan de igualdad en las pymes al amparo de la nueva ley de igualdad, 2007, cit., pág. 19. sistema logra examinar ecuánimemente la calidad y el nivel de cumplimiento de la actividad laboral; si además se puede realizar mediante parte de la jornada a través de jornadas flexibles o el teletrabajo. La medida, adicionalmente, conciliará oportunamente las responsabilidades laborales y familiares de la trabajadora, o del trabajador en su caso. En la práctica de la negociación, estas y otras medidas - como el estudio de los perfiles profesionales de las candidatas con potencial para el ascenso, vetando cualquier penalización para la promoción por el hecho de flexibilizar el tiempo de trabajo al tener menores o dependientes a su cargo-son ejemplos de buenas prácticas a incorporar en los planes. ${ }^{28}$ En los últimos años las nuevas formas de liderazgo que aportan las mujeres en los equipos directivos se están considerando un valor añadido en determinadas estructuras empresariales; de hecho, el establecimiento de cuotas en los equipos directivos es una recomendación presente en la mayoría de los manuales analizados, ${ }^{29}$ tratándose de una materia en la que resulta imprescindible detenerse.

La obligatoriedad del establecimiento de un porcentaje de mujeres en los equipos directivos se encuentra en el art. 75 Lor que determina que "las sociedades obligadas a presentar cuenta de pérdidas y ganancias no abreviada procurarán incluir en su Consejo de administración un número de mujeres que permita alcanzar una presencia equilibrada de mujeres y hombres en un plazo de ocho años" a partir de la entrada en vigor de la LOI. Por otro lado, la Disposición Adicional Primera aclara que se entenderá por composición equilibrada, cuando las personas de cada sexo "no superen el sesenta por ciento ni sean menos del cuarenta por ciento" en su conjunto. La importancia de esta presencia se evidencia en que es uno de los criterios tenidos en cuenta para la concesión del distintivo para las empresas en materia de igualdad (art. 50.4 LOI). Por su parte, el art. 52 LOI recoge el principio de presencia equilibrada de mujeres y hombres en los órganos directivos de la Administración General del Estado y organismos públicos vinculados o dependientes de ella. Esta determinación de presencia femenina en el ámbito de la administración general del

28 Fundación Mujeres - Junta de Extremadura. Buenas prácticas para integrar la igualdad de género en las empresas, 2006, pág. 39.

29 Ejemplos de ello: Manual para elaborar un Plan de Igualdad en la empresa. Aspectos básicos, cit., pág. 13; Instituto Andaluz de la Mujer, Consejería para la Igualdad y Bienestar Social. Planes de igualdad en empresas, pág. 16; Planes de igualdad en el sector agroalimentario, cit., pág. 22, este último establece un porcentaje del $40 \%$ de presencia femenina en las categorías profesionales subrepresentadas. 
Estado, también se establece para los órganos de selección de personal (art. 53) y en los órganos colegiados, comités de personas expertas o comités consultivos, nacionales o internacionales en los que esté representada la citada administración (art. 54). Todas estas medidas tienen como plazo límite de implantación el 2015 y su objetivo es franquear el conocido como "techo de cristal" aliviando la infra representación femenina en los órganos directivos de las empresas que es sólo del 13,7\% en Europa, teniendo España sólo un 11,5\%, por lo que de seguir esta tendencia se tardarían 40 años en alcanzar un $40 \%$ de presencia de mujeres. ${ }^{30}$

Desafortunadamente, en el ámbito comunitario la conquista de los puestos directivos por las empleadas femeninas ha sufrido un revés que no es consecuente con la trayectoria general del derecho social europeo en esta materia, que básicamente ha fijado el contenido obligatorio en materia de igualdad de género de las legislaciones nacionales menos progresistas en este tema, como ha sucedido en el caso español. La propuesta de Directiva para acelerar el progreso hacia un mejor equilibrio de género en los consejos de administración de las empresas europeas - que fijaba como plazo de transposición hasta el 2020, y pretendía ser aplicable en empresas de más de 2.500 empleados o con ingresos superiores a 50 millones de euros- ${ }^{31}$ ha sido pospuesta por la Comisión Europea, lo que desde luego supone un retroceso importante en el proceso de equiparación laboral femenina en Europa y ensombrece los avances conquistados durante décadas; que las mercantiles sean dirigidas mayoritariamente por varones, en la mayoría de las ocasiones, perpetúa la aplicación de patrones machistas en la cultura empresarial.

\section{La formación ocupacional}

La formación y la recualificación profesional en el seno de la empresa es complicada, pues el diseño de una formación sensible al género debe sortear numerosos factores estructurales discriminatorios, y atender dos aspectos diferentes del proceso formativo: el acce-

30 Base de datos de la Comisión Europea sobre mujeres y hombres en la toma de decisiones: http://ec.europa,eu/justice/gender-equality/genderdecision-making/database/index_en,htm, 24.12.2012.

31 Hubiera sido aplicable en torno a 5.000 empresas europeas: http:// europa.eu/rapid/press-release_IP-12-1205_es.htm , 24.12.2012. La propuesta de Directiva: Proposal for a Directive of the European Parliament and of the council on improving the gender balance among non-executive directors of companies listed on stock exchanges and related measures, Bruselas, 14.11.2012, com(2012) 614 final, 2012/0299 (cod). so a la formación y el contenido de dicha formación. Las ventajas de superar estereotipos ocupacionales cualificando a la mano de obra femenina son, desde la perspectiva empresarial, muy valiosas pues "resulta positivo para generar innovación, competitividad y lealtad del personal (...) y se traduce en una asignación más eficaz de la mano de obra, mayor productividad y producción total, aumento de la competitividad global y mejor formación del capital humano para la siguiente generación", además de ser una herramienta muy eficaz para combatir las múltiples dimensiones de la pobreza a nivel global. ${ }^{32}$

Testar que la formación prevista en la empresa atiende convenientemente al principio de igualdad ${ }^{33}$ precisa, en primer término, recabar qué porcentajes de mujeres y hombres han asistido a los cursos formativos disgregados por la tipología del curso (por ejemplo: idiomas, informática, habilidades interpersonales, gestión del tiempo, gestión de estrés, liderazgo, comunicación) y, en caso de una menor presencia femenina, indagar en las causas y en las medidas adoptadas por la empresa para evitar este déficit. Es importante evaluar los procedimientos de difusión de las ofertas de formación y los criterios de selección para decidir qué parte de la plantilla los realiza. Las posibilidades de acceso de la trabajadora a la formación están íntimamente relacionadas con cuestiones como la voluntariedad-obligatoriedad de las acciones formativas o su realización dentro o fuera de la jornada laboral, la posibilidad de su seguimiento mediante medios telemáticos que permitan conciliarlos con otras ocupaciones, o si los cursos ofertados fuera del horario laboral son preferentemente dirigidos a unos tipos de ocupaciones en la empresa pertenecientes a un nivel profesional determinado. También resulta conveniente diagnosticar si se fomenta la formación externa a la empresa mediante algún tipo de ayuda económica y si existe algún tipo de formación en la empresa sobre igualdad de oportunidades. En segundo lugar es necesario analizar si existe - y qué contenido tiene- el Plan de formación en la empresa, cómo se detectan las necesidades formativas, qué tipo de cursos se han impartido en los últimos años (de especialización técnica, de desarrollo de carrera, de for-

\footnotetext{
32 S. Ameratunga \& M. Kawar. Directrices para incluir la perspectiva de género en las políticas de empleo. (Informe de políticas 5: "Calificaciones y empleabilidad”), Organización Internacional del Trabajo, Departamento de Políticas de Empleo, Ginebra, 2011, pág. 4.

33 Manual para elaborar un Plan de Igualdad en la empresa. Aspectos básicos, cit., págs. 54-60.
} 
mación genérica...) y quién determina estas cuestiones y de acuerdo con qué criterios.

La práctica general de las guías advierte sobre la conveniencia del establecimiento de la formación continua en horario laboral, el establecimiento de ayudas económicas cuando la formación no pueda realizarse en la jornada laboral, vincular las acciones formativas al acceso a la promoción profesional, el fomento de la formación de mujeres en los puestos con menor presencia, el derecho de la formación de las trabajadoras que ejercen un derecho de reducción y excedencia de jornada para conciliar vida personal y vida laboral, ${ }^{34} \mathrm{o}$ el establecimiento de medidas de acompañamiento y cuidado de los hijos durante el tiempo de formación, si esta se realiza fuera del horario laboral. ${ }^{35}$ Para la conciliación entre trabajo y formación, determinados manuales recomiendan contemplar la formación en modalidad semipresencial; crear un aula virtual de formación vía intranet; incorporar la perspectiva de género en todos los cursos de formación que la empresa dirija a su personal, e incluir un módulo de igualdad de oportunidades en todos los cursos de formación que organice la empresa. ${ }^{36}$

Como conclusión, y partiendo de la premisa general de que "los altos niveles de desigualdad son un impedimento para el crecimiento económico, pues estos aumentan la pobreza y retrasan la justicia social", en lo que atañe concretamente a la formación ocupacional de la mano de obra femenina según destacan informes internacionales

[...] la infrautilización de las calificaciones de las mujeres provoca un desperdicio de recursos humanos y ahoga la innovación y la creatividad. Para competir a nivel mundial, los países deben hacer un uso pleno y eficaz de su capital humano; y, por lo menos la mitad de ese capital humano, incluye a las mujeres. ${ }^{37}$

\section{Condiciones salariales}

34 Planes de igualdad en el sector agroalimentario, cit., pág. 20. Guía para la implantación de un plan de igualdad en las pymes al amparo de la nueva ley de igualdad, cit., págs. 19-20.

35 Guía para la implantación de un plan de igualdad en las pymes al amparo de la nueva ley de igualdad, cit., pág. 20.

36 Manual para la implantación de Planes de Igualdad en las Empresas de Economía Social. Federación empresarial de mujeres para la economía social de Andalucía, Instituto Andaluz de la Mujer, Consejería para la Igualdad y Bienestar Social, 2009, pág. 17.

37 S. Ameratunga \& M. Kawar. Op. cit., pág. 3.
Los dos aspectos básicos a evaluar respecto al sistema retributivo son el cumplimiento del derecho universal de equiparación salarial por un trabajo de igual valor, y el establecimiento de salarios base y complementos salariales no discriminatorios. Determinadas guías enuncian directamente que el PI debe garantizar el "principio de igual remuneración por trabajos equivalentes" ${ }^{\text {" }}$ derecho garantizado internacionalmente hace décadas. El Convenio oIt sobre igualdad de remuneración, № 110 de 1951, establece la obligación de garantizar por parte de las legislaciones nacionales una idéntica retribución por un "trabajo de igual valor" y no "por un mismo trabajo", criterio que entre dos prestaciones comparables evita las discriminaciones salariales camufladas en circunstancias como la modalidad contractual, la categoría profesional, o los complementos salariales que corresponden a una u otra actividad laboral, formalmente diferentes, pero cuyo contenido real es análogo. Sin embargo, en nuestro país la discriminación salarial sigue siendo frecuente y además se manifiesta en varios sentidos: ${ }^{39}$ en primer lugar, la brecha salarial en España entre sexos ha aumentado de 5.292 a 5.745 euros y ha subido de 28 a 29,1 puntos porcentuales. Esta elevada y creciente diferencia obedece a diferentes variables tales como la jornada laboral, el tipo de contrato, la ocupación laboral, el sector de actividad, o los diferentes componentes del salario. También resulta determinante de esta ruptura al principio de igualdad salarial, la existencia de sectores masculinizados mejor retribuidos que los ocupados preferentemente por mujeres. Tal y como desvelan los estudios en la materia, en el sector servicios en el que existe una tasa de ocupación femenina porcentualmente más alta que en sectores como el industrial, el salario medio es menor $y$, además, la diferencia salarial media entre hombres y mujeres es mayor a la de otras ocupaciones. Adicionalmente, se acusa una mayor brecha salarial por sexo en la contratación indefinida frente a la temporal; "esta mayor remuneración de las personas asalariadas indefinidas se produce tanto entre los hombres como entre las mujeres, pero no con la misma intensidad. La ganancia media masculina mejora claramente de un contrato temporal a uno indefinido $(+56 \%)$, en mayor medida de lo que mejora la ganancia femenina entre un contrato temporal y uno indefinido $(+35 \%)$. Es decir, los hombres, además de contar con una ganancia

38 Planes de igualdad en el sector agroalimentario, cit., pág. 19.

39 AA.vv. Crisis y discriminación salarial de género. Op. cit., págs. 18, 24 y 34 ; el estudio analiza datos de 2008-2010. 
media superior a las mujeres en los contratos temporales, también logran aumentar más su ganancia media al contar con un contrato indefinido". ${ }^{40}$

Atendidas las altas tasas de incumplimiento de la igualdad retributiva, cualquier medida de acción positiva en esta materia debe diseñarse con un doble carácter correctivo y prevencionista, tratando en primer término de eliminar las discriminaciones existentes, y de otro lado, articulando las medidas necesarias para evitar que vuelvan a producirse situaciones discriminatorias en la empresa. En cuanto a los actos que lesionan el derecho a la igualdad de tratamiento por sexo en general, debe diferenciarse entre las discriminaciones directas, que se producen exclusivamente por la pertenencia a un género determinado, de aquellas que no estando fundamentadas en el sexo o que estándolo tienen una apariencia neutra, afectan mayoritaria o únicamente a un grupo específico de trabajadoras (discriminaciones indirectas o inversas). ${ }^{41}$ Los actos discriminatorios a través de medidas que aparecen formuladas aparentemente de manera neutra, pero que afectan a un porcentaje evidente más alto de mujeres que de hombres, se producen preferentemente en los criterios o pruebas para acceder al empleo, en las condiciones exigidas para ocupar un puesto determinado o ascender en la empresa, y sobre todo en materia salarial. Por ejemplo, se entiende como una discriminación indirecta, la diferencia salarial que afecta a una modalidad contractual ocupada mayoritariamente por mujeres en la empresa o en el sector productivo concreto (por ejemplo, contratadas a tiempo parcial con un salario proporcionalmente menor al de los trabajadores a tiempo completo en la empresa o en el sector).

En cuanto a la detección de discriminaciones en esta materia, en primer término debe diferenciarse dentro de la estructura retributiva entre el salario base abono fijado habitualmente por unidad de tiempo o de obra-, y los complementos salariales, que se determinan en función de circunstancias relativas a condiciones personales del trabajador(a), a la cantidad o calidad del trabajo realizado, o a la situación o resultados de la empresa. En el establecimiento del salario base se debe evitar la segregación de categorías o grupos profesionales por sexo, y atribuir idéntico salario base a categorías

40 Ibídem, pág. 34.

41 Cfr.: C. Sáez Lara. Mujeres y mercado de trabajo: las discriminaciones directas e indirectas. Consejo Económico y Social, Madrid, 1994; J. Cabeza Pereiro. Discriminación salarial indirecta por razón de sexo [Comentario a la TC s 58/1994, del 28 de febrero (BOE del 24 de marzo)]. RL, No 2, 1994. Diferencias de trato reguladas en el art. 6 LOI y art. 17.1 ET. diferentes en las que las tareas tengan el mismo nivel de complejidad, responsabilidad, fatiga, o nivel de formación. Tal y como ha advertido la jurisprudencia constitucional, la determinación de las categorías y grupos profesionales debe efectuarse mediante reglas comunes para trabajadoras y trabajadores, siendo precisa "la utilización de criterios neutros, con exclusión de los sexualmente caracterizados, por corresponder a los rasgos medios de la capacidad del varón". ${ }^{42}$ Ejemplos de prácticas contrarias al principio de igualdad retributiva son, por ejemplo, la determinación de un salario base menor para los trabajadores temporales o el establecimiento de una edad de jubilación diferente para mujeres y hombres, estando la pensión de jubilación comprendida en el concepto global de salario y, por tanto, tutelada por el principio de igualdad. ${ }^{43}$

Es frecuente que la discriminación retributiva se camufle en el reconocimiento de determinados complementos a categorías o niveles profesionales o actividades desempeñadas, exclusiva o mayoritariamente por trabajadores varones. Esta operación suele producirse utilizando complementos como el de antigüedad, toxicidad, peligrosidad o nocturnidad, disposición horaria, o complementos vinculados al puesto de trabajo. En el diseño del pi es recomendable utilizar incrementos salariales más objetivos o neutros que valoren la formación del trabajador (complementos personales por titulación, idiomas) o los vinculados a los resultados de la empresa o a la cantidad y calidad del trabajo. En este sentido, que los complementos salariales no sean discriminatorios depende de una valoración objetiva de la clasificación profesional, que atienda a criterios verídicos sobre las auténticas características del trabajo; en suma, la paridad retributiva debe partir de una clasificación profesional no sexista que efectúe una

42 Sentencia del Tribunal Constitucional Español 250/2000, de 30 de octubre [RTC 2000, 250]. Vetando estas discriminaciones: art. 28 et: "El empresario está obligado a pagar por la prestación de un trabajo de igual valor la misma retribución, satisfecha directa o indirectamente, y cualquiera que sea la naturaleza de la misma, salarial o extrasalarial, sin que pueda producirse discriminación alguna por razón de sexo en ninguno de los elementos o condiciones de aquella”.

43 Sentencia tice de 13 de noviembre de 2008, Asunto c-46/07, Comisión contra República Italiana. El adecuado tratamiento del derecho social comunitario de la paridad salarial por sexo en las última décadas tuvo, sin embargo, un origen no fundamentado en razones exclusivamente sociales primando en su adopción una justificación económica; la Directiva 75/117/CEE del Consejo, de 10 de febrero de 1975, relativa a la aplicación del principio de igualdad de retribución, fue implantada para evitar el dumping retributivo del sector textil italiano que perjudicaba el derecho a la competencia en el mercado exterior de los países que sí aplicaban la equiparación salarial (que además durante años se reconoció normativamente sólo para un mismo trabajo, y no para un "trabajo de igual valor"). 
evaluación de puestos de trabajo neutra y ecuánime. De esta forma debe entenderse contrario a este derecho, por ejemplo, el establecimiento de una remuneración menor para las horas extraordinarias en el contrato a tiempo parcial, modalidad contractual preferentemente utilizada con mujeres, o el reconocimiento de un plus salarial sólo a los trabajadores fijos.

Los documentos técnicos que sugieren las premisas para elaborar planes de acción positiva señalan muy oportunamente la importancia de revisar el salario correspondiente a los grupos, categorías o niveles profesionales en relación con el nivel de estudios y disgregar la partida salarial por puestos de trabajo y sexo, con y sin complementos, para testar si el salario base en realidad se establece correctamente. ${ }^{44}$ Es imprescindible, además, revisar que los complementos salariales no priman exclusiva o indebidamente condiciones como peligrosidad, toxicidad, esfuerzo físico, disponibilidad o dedicación plena. ${ }^{45}$ Medidas como promover que más hombres soliciten la reducción de jornada y salario por cuidado de un menor, mediante campañas de sensibilización acerca de la importancia de cooperar en el cuidado de menores ${ }^{46} \mathrm{o}$ establecer indicadores para verificar la razonabilidad de la promoción económica que no conlleve un cambio de grupo o categoría profesional son ejemplos válidos a implantar en las empresas, con independencia del sector productivo al que pertenezcan. ${ }^{47}$

\section{E. Ordenación del tiempo de trabajo y conciliación de la vida laboral, personal y familiar}

El art. 44.1 LoI ordena que los derechos de conciliación deben fomentar "la asunción equilibrada de las responsabilidades familiares, evitando toda discriminación basada en su ejercicio" permitiendo con esta fórmula tan abierta que en la práctica se planteen medidas de diverso contenido. Normalmente los objetivos de los planes de igualdad en la materia, tratan de fomentar la corresponsabilidad en las tareas de atención al núcleo familiar, o bien están destinadas a permitir un uso flexible o reducido de la jornada por parte del trabajador(a)

44 Manual para elaborar un Plan de Igualdad en la empresa. Aspectos básicos, cit., págs. 34, 36-37

45 Planes de igualdad en el sector agroalimentario, cit., pág. 19. 46 Aclarando algunas dudas sobre planes de igualdad, cit., pág. 87.

47 Guía para la elaboración de planes de igualdad en las empresas, Secretaría de Igualdad de UGT-Madrid, cit., pág. 37. que tenga algún tipo de cargas familiares, posibilidades que cuando no conllevan una penalización económica son completamente idóneas para alcanzar los objetivos de compatibilización de tareas. Sin perjuicio de la vinculación existente entre la práctica total de las condiciones laborales entre sí, y en general de la situación laboral de la trabajadora respecto a sus situación vital, la materia de la conciliación es perfecta para aplicar la transversalidad de las medidas de género, pues precisamente son medidas que inciden en condiciones ajenas al espacio productivo propiamente dicho, y además de diferente naturaleza (familiar, personal, económica, cultural). El concepto de transversalidad ha supuesto un avance importante en materia de igualdad de género, e implica superar el contenido internacional básico presente en la Carta Fundacional de Naciones Unidas de 1945 (art. 55) o en la Declaración Universal de Derechos Humanos de 1948 (art. 2), en las que se manifiesta que toda persona debe disfrutar de los derechos y libertades sin distinción alguna de raza, color, sexo, idioma, religión, opinión política o de cualquier otra índole, origen nacional o social, posición económica, nacimiento o cualquier otra condición. Sólo hasta 1979 cuando se supera esta indefinición sexual de la normativa, que evidentemente perjudica la diferente y peor situación de la mujer en el mundo, mediante la Convención de Naciones Unidas sobre la Eliminación de todas las formas de Discriminación contra la Mujer de 1979, que en su art. 11 establece el derecho a las mismas oportunidades en el empleo, en el ascenso en el trabajo, en la estabilidad laboral, la formación profesional, y a la igualdad en la remuneración e igual trato con respecto a un trabajo de igual valor, así como el derecho a recibir un tratamiento equitativo respecto a la evaluación de la calidad del trabajo y a la protección de la salud o a la seguridad en las condiciones laborales. Pero las particularidades y la gravedad de la discriminación existente contra la mujer en el mundo son puestas de manifiesto aún más recientemente, en la Iv Conferencia Mundial sobre las Mujeres de 1995 (ONU) - conocida como Conferencia de Beijing — en la que se acuña el término de transversalidad, tratando de resolver la confluencia de factores de diversa índole que afectan la deficiente situación de la mujer, por lo que las medidas tendentes a alcanzar un tratamiento igualitario deben ser "transversales", eliminando las desigualdades presentes en el ámbito cultural, religioso, político y económico. En la práctica - sin perjuicio de que la conciliación laboral y personal sea una materia especialmente idónea-implementar esta orientación heterogénea en un plan de acción positiva significa que se debe revisar 
cualquier aspecto relacionado con la prestación laboral, que incida directa o indirectamente en la igualdad de condiciones y oportunidades en el empleo, quedando sólo excluidas las materias que lo son en cualquier proceso de negociación colectivo o individual por tratarse de derecho necesario absoluto. ${ }^{48}$ Precisamente porque las dificultades de conciliar una actividad asalariada y la atención del núcleo familiar provocan una discriminación económica y social de la mujer, los recortes económicos que se están produciendo en materias como la dependencia inciden dramáticamente sobre el colectivo femenino, pudiendo calificarse como una forma de violencia económica contra la mujer. Adicionalmente, la reforma operada mediante la Ley 3/2012, de 6 de julio, ha trasladado indebidamente el incremento del poder empresarial al ámbito personal de los trabajadores con responsabilidades familiares legalmente tutelado. Tal y como apunta la doctrina. ${ }^{49}$ La Disposición Final primera de esta reforma que modifica el art. 37 ET, está provocando la imposibilidad de compatibilización de trabajo y atención a las responsabilidades familiares, situación agravada por la eliminación de la indemnización por despido, extinción que afectará mayoritariamente al colectivo femenino. La reforma del art. 37.4 ET ha consistido en la reformulación de sus beneficiarios en términos neutros, interpretando erróneamente la jurisprudencia comunitaria que señaló la necesidad de regular este derecho en términos de corresponsabilidad, obviando la necesidad de que el reparto del derecho debe hacerse entre varios posibles titulares de este. En cuanto a la reforma del permiso de lactancia (art. $37.5 \mathrm{ET}$ ), se reduce el derecho de ajuste de este al obligar a su cómputo diario, lo que evidentemente perjudica la necesaria planificación de la conciliación por la trabajadora. Por otro lado, por medio de la reforma del art. $37.6 \mathrm{ET}$, se admite la posibilidad de que la reducción de jornada motivada en la conciliación se concrete en la negociación colectiva, en atención a "las necesidades productivas y organi-

48 Además de transversal, cualquier plan de igualdad debe ser colectivointegral, dinámico, sistemático y coherente, flexible y temporal; Manual para elaborar un Plan de Igualdad en la empresa. Aspectos básicos, cit., pág. 7.

49 M.A. Ballester Pastor. De cómo la reforma operada por el RD Ley 3/2012 ha degradado el derecho fundamental a la conciliación de responsabilidades. RDS, № 57, 2012, pág. 108. Compartimos la opinión de la autora, que en relación a esta reforma laboral inconstitucional opina que "destaca, pero a estas alturas no sorprende, que el Gobierno, no haya tenido reparos en olvidar hacer referencia a una garantía de tamaña relevancia en relación con los derechos de conciliación”, pág. 114. El recorte de derechos laborales operado es tan grave que, desde luego, en esta materia, no queda compensado por las mejoras introducidas en la anterior reforma mediante la Ley 35/2010, que fueron calificadas de “irrisorias”; J. Cabeza Pereiro. Op. cit., pág. 10. zativas de las empresas", supeditando de esta forma un derecho que ya estaba conquistado, sin más condición a la conveniencia del empresario. Finalmente se condiciona el derecho al disfrute posterior de las vacaciones cuando coincida con el permiso de paternidad o con la incapacidad temporal incorporando límites temporales máximos (art. 38.3 ET).

En cuanto al contenido de las medidas en materia de conciliación, la mayor parte de estas hacen referencia al tiempo de trabajo, bien sea en relación con el horario de trabajo o a la duración de la jornada. Efectivamente esta materia tiene un "efecto desproporcionado sobre las mujeres" te se ocupan todavía del cuidado de la familia, y las diferentes guías proponen concretamente, por ejemplo, el uso fraccionado de los permisos retribuidos, ${ }^{51}$ introducir cláusulas de flexibilidad en la jornada, incluso en turnos, y de los permisos retribuidos, excedencias reducidas y fraccionadas, y puestos de trabajo compartidos; también introducir cláusulas para reducir la jornada mediante jornadas continuadas o jornadas partidas con descansos cortos, implantar un transporte colectivo, permitir el cumplimiento de parte de la jornada mediante el teletrabajo y celebrar videoconferencias en vez de desplazar al personal, cuando sea posible, y establecer en la negociación colectiva, a través del calendario laboral, distribuciones irregulares de la jornada para conciliar y coordinar con la representación legal el disfrute de jornadas especiales de las trabajadoras con responsabilidades familiares. ${ }^{52}$ Otras acciones positivas más específicas y detalladas pueden consistir en flexibilizar el horario de entrada y salida para compatibilizar los horarios escolares y de guarderías con la jornada laboral, creación de una bolsa de trabajo con personal especializado en asistencia y cuidado de personas dependientes, ofrecer la posibilidad de acumular las horas de lactancia para su disfrute tanto continuado como de forma flexible, $\mathrm{u}$ ofrecer permisos retribuidos para asistir a consultas médicas y para el acompañamiento de menores o personas dependientes. ${ }^{53}$ En otro orden de cuestiones y atendiendo situaciones personales de la trabajadora no relacionadas con el cuidado de dependientes, una posible medida a incluir es que no computen las ausencias al trabajo mo-

\footnotetext{
50 S. Ameratunga \& M. Kawar. Op. cit., pág. 6 (Informe de políticas 10 "Prácticas adecuadas en el lugar de trabajo")

51 Planes de igualdad en el sector agroalimentario, cit., pág. 22.

52 Ibídem, pág. 20.

53 Manual para la implantación de Planes de igualdad en las Empresas
} de Economía Social, cit., pág. 17. 
tivadas por violencia de género o la flexibilización del tiempo y lugar de trabajo, tal y como establecen determinados convenios colectivos de empresa que detallan una batería de medidas en tales supuestos. ${ }^{54}$

Aparte de las medidas sobre distribución del tiempo de trabajo, otras posibles directrices consistirían en establecer procedimientos objetivos para la movilidad geográfica, priorizando la permanencia de personas en situación de guarda legal ${ }^{55} \mathrm{y}$ es reseñable que la práctica total de las guías indican que la disposición de un servicio de guardería - propio de la empresa o concertado con una empresa externa- es un mecanismo de conciliación imprescindible, que en algunos casos se sustituye por una compensación económica para que la trabajadora opte por el centro infantil que mejor se adecue a sus necesidades. ${ }^{56}$ Efectivamente el cuidado

54 "La trabajadora víctima de violencia de género tendrá derecho, para hacer efectiva su protección o su derecho a la asistencia social integral: a) A la reducción de la jornada de trabajo con disminución proporcional del salario o a la reordenación del tiempo de trabajo, a través de la adaptación del horario, de la aplicación del horario flexible para la conciliación familiar, o de otras formas de ordenación del tiempo de trabajo que se utilicen en la Empresa, a decisión del interesado. b) En caso de verse obligada a abandonar el puesto de trabajo en la localidad donde venía prestando sus servicios, para hacer efectiva su protección o su derecho a la asistencia social integral, tendrá derecho preferente a ocupar otro puesto de trabajo, del mismo grupo profesional o nivel salarial equivalente que la Empresa tenga vacante en cualquier otro de sus Centros de Trabajo. En tal supuesto la Empresa comunicará a la trabajadora afectada por la violencia de género las vacantes existentes en dicho momento o las que se pudieran producir en el futuro. El traslado o cambio de centro de trabajo tendrán una duración inicial de seis meses, durante los cuales la Empresa reservará el puesto de trabajo que anteriormente ocupaba la trabajadora. Terminado este periodo, la trabajadora podrá optar entre el regreso a su puesto de trabajo anterior o la continuidad en el nuevo. En este último caso, finalizará la mencionada reserva. c) Suspender su contrato cuando se vea obligada a abandonar su puesto de trabajo como consecuencia de ser víctima de violencia de género. En este supuesto, el periodo de suspensión tendrá una duración inicial que no podrá exceder de seis meses, salvo que de las actuaciones de tutela judicial resultase que la efectividad del derecho de protección del trabajador afectado requiriese la continuidad de la suspensión. En este caso, por decisión judicial, se podrá prorrogar la suspensión por periodos de tres meses, con un máximo de dieciocho meses. d) A que no computen como faltas de asistencia, a los efectos del párrafo primero del artículo $52 \mathrm{~d}$ ) del Estatuto de los Trabajadores, las ausencias motivadas por la situación física o psicológica derivada de violencia de género, acreditada por los servicios sociales de atención o servicios de salud, según proceda. Será nulo el despido de las trabajadoras víctimas de violencia de género por el ejercicio de los derechos de reducción o reordenación de su tiempo de trabajo, de movilidad geográfica, de cambio de centro de trabajo o de suspensión de la relación laboral, en los términos y condiciones reconocidos en este Convenio", Convenio colectivo de la empresa Compañía Española de Petróleos, S.A. (Cepsa), Resolución del 18 de julio del 2011, cit., págs. 87692-87693.

55 Planes de igualdad en el sector agroalimentario, cit., pág. 20.

56 S. Ameratunga \& M. Kawar. Op. cit. págs. 5 y 7 (Informe de políticas

"Prácticas adecuadas en el lugar de trabajo"); Planes de igualdad en el de hijos es una de las cuestiones que más tiempo ocupa a la trabajadora del tiempo de trabajo, por lo que las medidas que valoren este aspecto pueden resultar muy adecuadas para compensarla; por ejemplo, a la hora de promover, podría puntuarse el hecho de tener hijos a su cargo menores de una edad determinada.

Con anterioridad a la LoI, la Ley 39/1999, de 5 de noviembre, ya introduce en nuestro espacio jurídico la conciliación laboral estableciendo básicamente un régimen de permisos y licencias, y algunas formas de flexibilización de la jornada para la mujer trabajadora. ${ }^{57}$ Por otra parte, la llamada a la negociación colectiva efectuada en el art. 34.8 ET para que por medio de ella se introduzcan reglas para un diseño de la jornada en términos de corresponsabilidad y conciliación, no se ha visto satisfecha a la luz de la realidad convencional de los últimos años. ${ }^{58}$ Afortunadamente, se comienza a vislumbrar un mayor compromiso en los planes de igualdad más recientes en dos ámbitos concretos: introduciendo medidas de conciliación que mejoran las previstas legalmente, y permitiendo fórmulas de flexibilización de la jornada consecuentes con la conciliación y la corresponsabilidad en la atención de las tareas familiares entre mujer y varón..$^{59}$ De entre las primeras, son reseñables el incremento de la duración de la suspensión de la maternidad, del tiempo de concesión de los permisos retribuidos por nacimiento de hijos o del disfrute de las excedencias familiares; también encontramos ejemplos de acumulación del periodo de lactancia, la concesión de permiso no retribuido para asistir al tratamiento de reproducción asistida, para la tramitación de la adopción internacional, o para el acompañamiento en la asistencia médica de familiares o emergencias familiares. En cuanto a otras fórmulas de flexibilización horaria arbitradas en los planes de igual-

sector agroalimentario, cit., pág. 20; Manual para la implantación de Planes de igualdad en las Empresas de Economía Social, cit., pág. 17.

57 Guías específicas en materia de conciliación: Instituto de la Mujer. Guía de buenas prácticas para conciliar la vida familiar y profesional. Madrid, 2001; Fundación Mujeres. La conciliación de la vida laboral, familiar y personal: Una estrategia que beneficia a las empresas. Información práctica para integrar la conciliación en las organizaciones laborales, 2007; Instituto Andaluz de la Mujer, Consejería para la Igualdad y Bienestar Social. Guía sobre conciliación de la vida laboral, familiar y personal, 2008

58 M.L. Molero Marañón. Medidas para conciliar la vida laboral y la vida personal y familiar. Análisis de medidas y planes de igualdad en la negociación colectiva, cit., págs. 40 y ss. Algunas excepciones a esta tónica general de los convenios colectivos, recogiendo mejoras a la regulación legal en págs. 43-44.

59 M.L. Molero Marañón. La conciliación laboral. Análisis de medidas y planes de igualdad en la negociación colectiva, cit., págs. 139-141. 
dad, además de la típica prevista para quienes tengan a su cargo a menores de una determinada edad (normalmente 10 o 12 años), o para el cuidado de familiares con discapacidad o mayores de 65 años, en la práctica se incluye la posibilidad de adaptar los horarios de trabajo a los horarios de las escuelas infantiles y de las necesidades de las personas dependientes, la creación de un horario especial para situaciones personales familiares graves, la posibilidad de una jornada especial posmaternidad durante un tiempo tras la incorporación de la trabajadora, o la alternativa de establecer una jornada flexible dividida en una jornada de presencia obligatoria y otra de presencia flexible en función de las necesidades personales y profesionales. En todo caso, debe procurarse que la conciliación no incida negativamente en la promoción profesional o en las condiciones concretas de la prestación laboral, y que las medidas de flexibilización del tiempo de trabajo puedan disfrutarse por los trabajadores varones para permitir una asunción equilibrada de las responsabilidades familiares. ${ }^{60}$

Pero no todas las guías aciertan en las medidas a implantar, por lo que resulta importante seleccionar las propuestas que en primer lugar se adapten a la estructura y las particularidades de la empresa, y además sean prácticas y efectivas. Proponer por ejemplo los "bancos de tiempo" como medida de conciliación no resulta ninguna de las dos cosas, pues una materia en la que se trata de la atención de menores o dependientes es preciso poner a disposición de la trabajadora el apoyo de servicios especializados y de confianza, por lo que esta propuesta - propia del asociacionismo vecinalno es oportuno ni tan siquiera en tiempos de crisis tal y como justifica la medida comentada; el compromiso de la empresa en el cumplimiento de la conciliación, en la mayoría de las ocasiones, no conlleva un desembolso económico importante - por ejemplo la mayoría de las fórmulas de flexibilización horaria-, pero el caso de los servicios internos o externos de guardería sí conlleva un gasto ineludible a asumir por la empresa. ${ }^{61}$

60 Ibídem, pág. 142; señalando esta presencia asimétrica en los trabajos reproductivos: A. Álvarez Montero. Prevención de riesgos laborales con perspectiva de género. Gestión práctica de Planes de Igualdad, cit., págs. 118 y ss.

61 La guía comentada propone otras medidas más adecuadas, como liberar la jornada de tarde de los viernes a las trabajadoras; sin embargo, el "banco de tiempo" o "dar libre el día del cumpleaños" restan seriedad, rigor y compromiso a este documento; Cuaderno de trabajo 3: Del discurso de la conciliación al discurso de la igualdad. Red Concilia, Área de Gobierno de Familia y Asuntos Sociales del Ayuntamiento de Madrid, 2009, págs. 22-23. En otro sentido - más acertado-, la propuesta de "bancos de tiempo libre" como medida que permite al personal
Finalmente cabe mencionar que la interpretación jurisprudencial del catálogo de derechos de la trabajadora que concilia trabajo y cuidado de familiares puede considerarse muy adecuada en algunos aspectos; concretamente la extinción contractual del contrato de obra o servicio de una trabajadora con reducción de jornada por guarda legal, se ha considerado automáticamente nula, al realizarse una interpretación extensiva del régimen legal que ampara a la trabajadora embarazada y la protege tanto frente al despido como a los actos preparatorios de este (sTs u.d. 16.10.2012). De esta forma, se aplica la doctrina constitucional que entiende que al estar comprometido un derecho fundamental debe aplicarse estrictamente el derecho a la tutela judicial efectiva (sTC 92/2008, del 21 de julio), constituyendo el derecho a la jornada reducida por guarda legal, una institución directamente vinculada con el derecho a la no discriminación por razón de sexo. Como consecuencia de ello, en estos supuestos es necesaria "una tutela más enérgica que la ordinaria frente a la discriminación", lo que supone que la trabajadora queda eximida de la acreditación de que "existe indicio alguno sobre la conculcación del derecho fundamental", declarándose automáticamente la nulidad. En lo que se refiere a la práctica convencional, encontramos manifestaciones de este respeto a los derechos de conciliación en determinados PI que se fijan como objetivos la garantía de "que el ejercicio de los derechos relacionados con la conciliación no supongan un menoscabo en las condiciones laborales de la plantilla", añadiendo que el disfrute de dichos derechos no puede suponer ningún tipo de discriminación, velando porque se disfruten por las personas con cualquier tipo de contrato y prestando un especial seguimiento en el caso de reincorporación al puesto de trabajo, de personas con contratos fijos discontinuos que han disfrutado reducciones por conciliación. ${ }^{62}$

\section{F. Otras materias}

Bajo este epígrafe, el art. 46.2 LoI permite que el plan de igualdad contenga todas aquellas materias que los negociadores estimen oportuno, tratándose de un instrumento dúctil que se adapta a las necesidades espe-

intercambiar sueldo por tiempo libre, lo que equivaldría a vacaciones no retribuidas, en: Fundación Mujeres, Ministerio de Trabajo y Asuntos Sociales, Instituto de la Mujer, Guía de buenas prácticas para conciliar la vida familiar y profesional. 2010, pág. 11.

62 Plan de Igualdad entre mujeres y hombres Sodexo España S.A. (201014), en: C. Bravo \& R. Gómez. Buenas prácticas en la negociación de los planes de igualdad. Op. cit., pág. 51. 
cíficas de cada mercantil en materia de igualdad. Sin embargo, la práctica totalidad de las guías incluye de manera individualizada la prevención de riesgos laborales bajo un epígrafe en el que se proponen una batería de medidas garantistas de la igualdad por sexo en salud laboral, aunque la LoI no la mencione expresamente.

De hecho, incluso en las guías, existe cierta confusión a la hora de proponer medidas en prevención de riesgos con orientación de género, concretamente respecto a su inclusión en epígrafes no específicamente relativos a la salud laboral; en algunos casos, se propone "incluir en la evaluación de riesgos laborales la reproducción, lactancia y el estrés" o "incluir actividades relacionadas no consideradas como enfermedades profesionales" dentro del apartado "Condiciones laborales y salud", junto con otras cuestiones no concretamente dedicadas a la prevención de riesgos. ${ }^{63}$ Con la misma sensibilidad que reconoce que fisiológicamente la trabajadora puede generar patologías específicas en el lugar de trabajo, es típico que se incluya la detección de riesgos laborales propios de las mujeres a la hora de elaborar el Plan de Riesgos Laborales, la inclusión en los reconocimientos médicos oficiales del reconocimiento ginecológico, promover el desarrollo de actuaciones preventivas dirigidas a las trabajadoras con exposición a riesgos en circunstancias especiales asociadas con la maternidad y lactancia, y elaborar estadísticas periódicas, desagregadas por sexo, recogiendo y valorando aspectos relativos a la salud laboral. ${ }^{64}$

En cuanto al catálogo de materias de diversa índole que se sugieren en los instrumentos técnicos para la elaboración de PI, encontramos la responsabilidad social corporativa, medidas para mujeres en situación o riesgo de exclusión, ${ }^{65}$ siendo además común que se traten dos cuestiones: los problemas de representatividad de la mujer en la empresa, y la comunicación, el lenguaje y la imagen no sexista en la empresa. Respecto a la primera materia, las buenas prácticas recomendadas como objetivos a conseguir en la empresa, tratan de equilibrar la representación femenina-masculina en

63 Planes de igualdad en el sector agroalimentario, cit., pág. 22. 64 Manual para la implantación de Planes de Igualdad en las Empresas de Economía Social, cit., pág. 74. Otras guías para esta modalidad productiva: Elkar-Ikertegia, S.Coop.And. Guía para la implantación de medidas de igualdad en las Cooperativas. Dirección General de Economía Social del Gobierno Vasco, 2008; Confederación Española de Cooperativas de Trabajo Asociado. Guía para la elaboración de planes de igualdad en cooperativas de trabajo asociado, 2008.

65 Manual para elaborar un Plan de Igualdad en la empresa. Aspectos básicos, cit., págs. 49 y 80 la negociación colectiva y el acceso de mujeres a puestos de responsabilidad y de dirección y gestión; también tratan de promover la composición paritaria del Consejo de Administración y los órganos directivos de la empresa; garantizar la equidad entre géneros en los actos de representación de la empresa; promover la formación y representación de agentes de igualdad dentro de la empresa; transmitir clara y explícitamente el compromiso social de la empresa con respecto a la equidad entre géneros en actos de representación, o promover el asociacionismo interno para la participación-acción de la empresa en proyectos para la promoción de la igualdad de oportunidades. ${ }^{66}$

En cuanto a la comunicación, lenguaje e imagen no sexista, conviene que se incluya entre las materias del plan de igualdad puesto que "la publicidad no sexista de los productos o servicios de la empresa" es uno de los criterios evaluados para conceder el distintivo de igualdad de las empresas previsto en el art. 50.4 LOI. Los manuales indican que los objetivos a cumplir en la materia van desde revisar las publicaciones internas y externas de la empresa, o la actualización del lenguaje del convenio colectivo, eliminando todo estereotipo sexista en imágenes o textos de la empresa. ${ }^{67}$

Las posibilidades a la hora de incluir diferentes cuestiones en la llamada general efectuada en el precepto, permiten que puedan establecerse medidas de tutela de la trabajadora embarazada atendida la frecuente extinción laboral basada en esta causa discriminatoria. Concretamente se defiende que en el plan podría articularse un procedimiento de fiscalización en los supuestos de despido de trabajadoras embarazadas similar al expediente contradictorio previsto para los despidos de representantes de los trabajadores del art. 55.1 ET. ${ }^{68}$ En esta materia es preciso mencionar que la interpretación jurisprudencial ha acomodado convenientemente la regulación sobre despido con la tutela de la trabajadora en situación de embarazo o en situaciones conexas con este, estableciendo que no es necesario que el empresario conozca la situación de embarazo para que el despido se declare nulo con base en el art. 55.5.b) ET (sTC 17.10.2008 y STC 92/2008, del

66 Manual para la implantación de Planes de Igualdad en las Empresas de Economía Social, cit., pág. 75. También en: Manual para elaborar un Plan de Igualdad en la empresa. Aspectos básicos, cit., pág. 75.

67 Planes de igualdad en el sector agroalimentario, cit., pág. 22; Manual para elaborar un Plan de Igualdad en la empresa. Aspectos básicos, cit., pág. 69.

68 G. Fabregat Monfort. Los planes de igualdad como obligación empresarial, págs. 71-73. 
21 de julio), doctrina atemperada posteriormente al defenderse que la declaración de nulidad no impide la posterior extinción del contrato temporal de la trabajadora (sTs 28.04.2010). ${ }^{69}$

\section{TRatamiento Del acoso SEXUAL O POR RAZÓN DE SEXO EN GUÍAS Y MANUALES}

\section{A. La obligatoriedad de los protocolos contra el acoso con independencia del tamaño de la empresa}

Con carácter previo al análisis de los protocolos contra el acoso recomendados en diferentes documentos técnicos, nos detendremos en dos aspectos de la regulación legal que han tenido que ser interpretados por la doctrina: la existencia de los protocolos contra el acoso laboral asociados con un PI o de existencia autónoma, y el innecesario consentimiento de la víctima en los supuestos de acoso sexual laboral. En cuanto a la primera de las cuestiones, los procedimientos para prevenir y solventar el acoso sexual o por razón de sexo se mencionan en el art. 46.2 LOI como una materia de obligatoria revisión en un plan de acción positiva. Sin embargo, el art. 48 se detiene específicamente en la prevención de esta modalidad de acoso, estableciendo que las empresas no sólo deben propiciar y asegurar un ambiente laboral libre de este tipo de conductas, sino que, adicionalmente deben "arbitrar procedimientos específicos para su prevención y para dar cauce a las denuncias o reclamaciones que puedan formular quienes hayan sido objeto del mismo". De la lectura conjunta de los arts. 46 y 48 se concluye que el contenido de los planes de igualdad puede ser variado, y más o menos extenso dependiendo de las condiciones de respeto al principio de igualdad presentes en la empresa, pero en todo caso deben adoptarse procedimientos específicos de prevención y para dar cauce a las denuncias en materia de acoso.

Los PI enunciados en el art. 45 son de existencia obligatoria en tres supuestos: empresas de más de 250 trabajadores(a)s, cuando así lo recoja el convenio colectivo de aplicación a la empresa, y cuando la autoridad laboral hubiera acordado en un procedimiento

69 A. Martín Valverde, F. Rodríguez-Sañudo Gutiérrez \& J. García Murcia. Derecho del trabajo, págs. 796-797, Tecnos, Madrid, 2011. sancionador la sustitución de las sanciones accesorias por la elaboración y aplicación de dicho plan, en los términos que se fijen en el indicado acuerdo (art. 45 en sus números 2,3 y 4 ). Fuera de estos supuestos, la implantación de un PI en la empresa es voluntario para el empresario (art. 45.5). La circunstancia de que los procedimientos contra el acoso se enuncien como uno de los posibles contenidos de los PI plantea la duda de si su existencia sólo será obligatoria en los tres casos expuestos; sin embargo, la mención contenida en el art. 48.1 - "las empresas deberán" - parece indicar dos cosas: las empresas deben establecer protocolos contra el acoso con independencia de su tamaño o de lo establecido en convenio, y en segundo lugar, los protocolos contra el acoso son materia de obligatoria existencia en cualquier plan de igualdad, bien formando parte de este o en un instrumento independiente que puede adoptar la forma de "códigos de buenas prácticas", tal y como menciona el art. 48.1 en su segundo párrafo..$^{70}$ En este sentido, es posible que la necesaria existencia de medidas específicas para prevenir este tipo de acoso en todo el tejido empresarial, sea muestra de un interés especial del legislador en erradicar estas violaciones al derecho a la dignidad personal tutelando convenientemente el derecho a la libertad sexual. Este tratamiento por separado de los planes de igualdad - que deben contener protocolos contra el acoso-y de los propios protocolos "independientes" de necesaria existencia, implica que las empresas de menos de 250 trabajadores o en las que sin importar su tamaño, el convenio colectivo de aplicación no establezca la obligatoriedad de negociar un PI, deben contar forzosamente con procedimientos específicos para prevenir la violencia sexual o sexista y para dar cauce a las denuncias en la materia. ${ }^{71}$ De este modo se desarrolla correctamente el derecho laboral básico enunciado en el art. 4.1.e) ET que garantiza la protección frente a este tipo de acoso, otorgando la necesaria cobertura a todos los trabajadores y trabajadoras independientemente del tamaño de la empresa, y que en la regulación dirigida a garantizar la igualdad en la función pública está convenientemen-

\footnotetext{
70 C.L. Alfonso Mellado \& G. Fabregat Monfortg. Los planes de igualdad en la administración pública. pág. 65, Bomarzo, Albacete, 2007; J.F. Lousada Arochena. Acoso sexual y acoso sexista. El principio de igualdad en la negociación colectiva. AA.vv. Lousada Arochena, J.F. (Coord.), pág. 364; J.M. Serrano García. La obligatoriedad de los convenios de proteger la dignidad de la mujer y el hombre en el trabajo. La conciliación de la vida laboral, familiar y personal en la negociación colectiva de CastillaLa Mancha, AA.vv. Bomarzo, Albacete, 2009, pág. 276.

71 A.M. Olmo Gascón. Op. cit., págs. 201-203.
} 
te resuelta, pues el art. 62 y la Disposición final sexta de la LoI se refieren a la obligatoriedad de estos sin sujeción a condición alguna y sin mencionar, en ningún caso, que deben formar parte de los PI. ${ }^{72}$ Por otro lado, la justificación de la existencia de estos mecanismos de prevención y resolución de conductas en todo tipo de empresas, da cumplimiento a la normativa española en materia de prevención de riesgos laborales que establece el deber del empresario de garantizar la seguridad y la salud de los trabajadores a su servicio "en todos los aspectos relacionados con el trabajo", debiendo realizar, en primer término, una labor de prevención de los riesgos. ${ }^{73}$ Sin embargo, esta tesis no ha prosperado en la práctica, pues las guías de recomendaciones parten de la premisa de que todo plan de igualdad debe contener un protocolo contra el acoso sexual o por razón de sexo, pero no indican la posibilidad de que cuando el PI no es obligatorio, la empresa deberá contar en todo caso con un protocolo contra el acoso por aplicación del art. 48 LOI. $^{74}$

\section{B. La irrelevancia del consentimiento de la víctima en algunos supuestos de acoso}

Una definición típica del acoso sexual o por razón de sexo en el trabajo que repara en tres posibles manifestaciones de este, establece que debe considerarse acoso sexual si dicha conducta es indeseada, irrazonable y ofensiva para la persona que es objeto de ella; en segundo lugar, si la negativa o el sometimiento de una persona a dicha conducta por parte de empresarios o trabajadores (incluidos los superiores y los compañeros) se utiliza de forma explícita o implícita como base

\footnotetext{
72 Defendiendo la obligatoriedad de los protocolos en todas las administraciones públicas y no sólo en la Administración General del Estado: C.L. Alfonso Mellado. Igualdad entre mujeres y hombres en la función pública. Albacete, Bomarzo, 2007, pág. 55. En cuanto a las guías en este ámbito, realizando una descripción muy apropiada de la metodología a seguir en las corporaciones locales, ver Federación Española de Municipios y Provincias, Secretaría General de Políticas de Igualdad, Instituto de la Mujer, Ministerio de Trabajo y Asuntos Sociales. Guía para elaborar Planes Locales de Igualdad. (2005).

73 T. Pérez del Río. La violencia de género en el ámbito laboral: el acoso sexual y el acoso sexista, págs. 55 y ss, Bomarzo, Albacete, 2009.

74 Sin indicar esta obligatoriedad y autonomía, ver: Aclarando algunas dudas sobre planes de igualdad, cit., págs. 52-53. De igual forma en la negociación colectiva, los protocolos contra el acoso se incluyen normalmente como parte de los PI; G. Fabregat Monfort. La negociación de los planes de igualdad en los convenios colectivos de ámbito sectorial. Negociando la igualdad en las empresas: estado de la cuestión y estrategias para la implementación de una política de igualdad de género, cit., pág. 83.
}

para una decisión que tenga efectos sobre el acceso de dicha persona a la formación profesional y al empleo, sobre la continuación de este, los ascensos, el salario o cualesquiera otras decisiones relativas al empleo y, finalmente, si además, o de forma independiente, dicha conducta crea un entorno laboral intimidatorio, hostil y humillante para la persona que es objeto de esta. ${ }^{75}$ Estas tres posibilidades nos plantean en primer término qué sucede con las conductas sexuales inapropiadas por ofensivas pero libremente aceptadas por la víctima, y con las que aparentemente son deseadas pero están mediatizadas por un vicio del consentimiento de la víctima, que accede condicionada por algún temor. ${ }^{76}$

En cuanto a la primera posibilidad, debe diferenciarse entre el acoso sexual vetado y el mero "comportamiento sexual en la empresa", pues el primero es indeseado y el segundo aceptado y mutuo, ${ }^{77}$ aunque se desenvuelva mediante hostilidades o resulte degradante desde el punto de vista de los posibles testigos, pertenece a la libertad de los sujetos de desarrollar su libertad sexual en los términos que estimen conveniente, a lo que cabe añadir que subjetivamente el derecho a la dignidad y a la integridad física y moral tiene unos márgenes generosos dependiendo de cada sujeto. En la praxis, numerosas guías para la elaboración de PI recogen que "el acoso sexual se distingue de las aproximaciones libremente aceptadas y recíprocas, en la medida en que no son deseadas por la persona que es objeto de ellas".78

75 Recomendación de la Comisión de Comunidades Europeas 92/131/ CE, del 27.11.1991.

76 La doctrina y la jurisprudencia condicionan el acoso al no consentimiento de la víctima; de esta forma, la doctrina destaca jurisprudencia procedente del TC, como la Sentencia 224/1999, de 13 de diciembre, que establece "el carácter no deseado de la agresión libidinosa y cómo, cuándo y con qué <<contundencia $>>$ ha de manifestarse ese carácter no deseado. En segundo lugar, la Sentencia 136/2001, de 18 de julio, que reitera el criterio de la Sentencia anteriormente citada y determina que $<<$ para que exista un acoso sexual ambiental constitucionalmente recusable ha de exteriorizarse, en primer lugar, una conducta de tal talante por medio de un comportamiento físico o verbal manifestado, en actos, gestos o palabras, comportamiento que además se perciba como indeseado e indeseable por su víctima o destinataria >>", G.M. Sobrino González. El acoso sexual y el acoso por razón de sexo. Análisis de medidas y planes de igualdad en la negociación colectiva, cit., pág. 57. Defendido con anterioridad: T. Pérez del Río, F. Fernández López \& F. Del Rey Guanter, Discriminación e igualdad en la negociación colectiva. Colección Estudios No 36, Ministerio de Asuntos Sociales, Instituto de la Mujer, Madrid, 1993, pág. 263.

77 Secretaría Confederal de la Mujer de ccoo. Guía sindical: el acoso sexual en el trabajo. $2^{\text {a }}$ ed., pág. 28, 2000.

78 Aclarando algunas dudas sobre planes de igualdad, cit., págs. 98-99. 
Pero evaluar como imprescindible el hecho del consentimiento de la víctima, sin más matizaciones, puede ocasionar la vulneración de un derecho fundamental en los casos en los que la voluntad de la víctima se encuentra influenciada o anulada por las circunstancias que rodean el acoso (aceptado por temor a sufrir consecuencias laborales, por ejemplo) y que, recordemos, supera una mera conducta sexual ordinaria pues se trata de manifestaciones ofensivas, intimidatorias u hostiles que denigran al acosador, a la víctima, y si se efectúan en público afectan al ambiente laboral de la empresa aunque se presenten como aparentemente consentidas. Resultan sorprendentes los resultados de las estadísticas efectuadas entre trabajadoras españolas en los que un amplio porcentaje cree que muchos acosos sexuales se permiten por temor a sufrir consecuencias laborales y además opinan que en bastantes ocasiones las trabajadoras utilizan comportamientos sexuales para acceder al empleo o mejorar en este. ${ }^{79} \mathrm{~A}$ este respecto es preciso aclarar que en muy pocas ocasiones el acoso se produce por una actitud complaciente de la víctima, por lo que debe desterrarse la idea de que es preciso soportar el acoso para conservar el trabajo o para ascender, prejuicios machistas que favorecen estas conductas. ${ }^{80}$

En la práctica ya se está reparando en este extremo y determinados planes de igualdad indican que también es acoso el consentido, cuando de su aceptación depende alguna mejora laboral o expectativa de derecho, ${ }^{81} \mathrm{y}$ en consonancia con esta interpretación en algunos PI se indica que los compañeros(a)s de la víctima deben denunciar las conductas acosadoras pudiendo iniciar el procedimiento contra el acoso existe en la empresa como testigos de las mismas, lo que en algunas ocasiones seguramente revelará auténticos acosos sexuales o por razón de sexo camuflados en relaciones aparentemente deseadas. ${ }^{82}$ Por ello, determinadas condiciones recogidas en la práctica de la negociación re-

79 Conducta esta última, que en cuanto indeseada hay que incluir como acoso sexual indirecto; T. Pérez del Río, F. Fernández López \& F. Del Rey Guanter. Op. cit., pág. 265

80 Instituto de la Mujer, Ministerio de Trabajo y Asuntos Sociales. El acoso sexual a las mujeres en el ámbito laboral. pág. 5 .

81 "b) si la negativa o el sometimiento de una persona a dicha conducta por parte de la empresa o trabajadores(a)s, se utiliza de forma explícita o implícita como base para una decisión que tenga efectos sobre el acceso de dicha persona a la formación profesional y al empleo, sobre la continuación del mismo, el salario o cualquiera otras decisiones relativas al empleo"; en el PI de Emulsa (sociedad anónima municipal) en: G.M. Sobrino González. Op. cit., pág. 161.

82 Ibídem, pág. 162 . sultan inconvenientes, pues sólo tutelan los acosos no deseados o queridos por la víctima sin más matices. ${ }^{83}$

De manera muy oportuna, el art. 7 Lor define el acoso sexual eliminando el elemento del consentimiento de la víctima, puesto que no se hace mención alguna al "comportamiento no deseado", referencia que sí se contenía en la Ley 62/2003 (art. 28). Para analizar esta diferencia en la normativa española y sopesar su significado, es necesario poner en relación la regulación contenida en este precepto con el resto de la regulación laboral que tutela a los trabajadores frente al acoso sexual o por sexo. En opinión de diversos autores, el hecho relevante para calificar el acoso no es el consentimiento de la víctima, pues es suficiente con que los actos del acosador tengan ese propósito o produzcan ese efecto, tal y como advierte el art. 7 de la Ley de Igualdad española. ${ }^{84}$ Es preciso resaltar que el art. 48 LOI establece como obligación la eliminación de cualquier tipo de acoso sexista en el espacio laboral, y como mecanismo de tutela la regulación del Estatuto de los Trabajadores en el art. 64.7.a). $3^{\circ}$ ) recoge entre los derechos de información y consulta de los comités de empresa y delegados de personal la capacidad de vigilar el respeto y la aplicación del principio de igualdad de trato y de oportunidades entre mujeres y hombres. Además, constituyendo el acoso sexual o por sexo una causa de despido disciplinario (art. 54.2.g), o tratándose de una cuestión también abordada por la normativa de prevención de riesgos laborales, el consentimiento de la víctima debería interpretarse adecuadamente no constituyendo un elemento determinante del ilícito laboral o de incluirse, especificando que en los supuestos en los que se encuentra influenciado por alguna amenaza, violencia o intimidación constituye acoso aunque la manifestación externa de la víctima aparentemente consienta la conducta. De esta forma, la regulación actual no tutela convenientemente el derecho laboral básico a "la protección frente al acoso sexual, el acoso por razón de sexo y el acoso por orientación sexual", pues desatiende un porcentaje de acosos sexuales laborales forzados que deberían ser reconocidos normativamente de forma explícita. En este sentido, se defiende que si una

83 Convenio colectivo de la empresa Compañía Española de Petróleos, S.A. (Cepsa), Resolución del 18 de julio del 2011, de la Dirección General de Trabajo, por la que se registra y publica el Convenio colectivo de Compañía Española de Petróleos, S.A., (BOE 02-08-2011), pág. 87680.

84 A. Vilches Arribas, T. Pérez del Río \& M. Hernández Canosa. Guía de criterios y cláusulas para el tratamiento del acoso sexual y moral por razón de género en la negociación colectiva. Dirección General de la Mujer, Madrid, 2004, pág. 26. 
conducta resulta ofensiva, cabe entenderse que automáticamente resulta indeseada. ${ }^{85}$

La disyuntiva se plantea entre si debe primar la tutela del derecho a la dignidad de la víctima, pues no debe olvidarse que el comportamiento ilícito debe tener como "propósito o el efecto de atentar contra la dignidad de una persona, en particular cuando se crea un entorno intimidatorio, hostil, degradante, humillante $\mathrm{u}$ ofensivo", o bien debe exigirse como elemento configurador del ilícito el carácter ofensivo de la conducta. Por ello el concepto recogido en el Acuerdo Marco Europeo sobre Acoso y Violencia en el Lugar de Trabajo, de abril del 2007, es el idóneo en el sentido de que no establece una definición unívoca de acoso sexista y sí una descripción de la conducta, soslayando en todo caso el elemento del consentimiento, pues

[...] la percepción subjetiva de los individuos frente a un determinado comportamiento es muy variable dependiendo de su propia manera de ser, su estado de ánimo, y está, además, supeditada a distintos elementos vinculados a su contexto personal, cultural, geográfico y laboral.

En este texto se parte de la premisa de que

[...] el acoso moral afecta directamente a la dignidad del trabajador, así como a la productividad y a la eficiencia en el trabajo. [...] Conviene por ello que las empresas subrayen que los supuestos de acoso moral no serán tolerados y que son contrarios a la cultura empresarial. ${ }^{86}$

85 T. Pérez del Río. La violencia de género en el ámbito laboral: el acoso sexual y el acoso sexista, Op. cit. págs. 31-32. Analizando la evolución de este elemento subjetivo en la normativa comunitaria: Quesada Segura, R. La protección y las medidas preventivas frente al acoso sexual en el trabajo, en desarrollo de la Ley 3/2007. Gestión práctica de Planes de Igualdad, cit. págs. 130 y ss.

86 Acuerdo de 08.11.2077, сом (2007) 686 final. En esta línea, la STC 224/1999, de 13 de diciembre, que evaluando el elemento del consentimiento de la víctima declara que para determinar la existencia de acoso sexual laboral no se requiere que la reacción de la víctima, tras las insinuaciones o contactos sea inmediata y contundente, sino que es suficiente una señal suficientemente expresiva del carácter no querido del acto. Destacar que el delito penal de acoso laboral en el trabajo — art. 184 $\mathrm{CP}$ - tipifica la conducta sin mencionar el consentimiento estableciendo como suficiente que el comportamiento provoque a la víctima una situación objetiva y gravemente intimidatoria, hostil o humillante; además establece como fórmula cualificada prevalerse "de una situación de superioridad laboral, docente o jerárquica, o con el anuncio expreso o tácito de causar a la víctima un mal relacionado con las legítimas expectativas que aquélla pueda tener en el ámbito de la indicada relación”, estableciendo como agravante que "la víctima sea especialmente vulnerable, por razón de su edad, enfermedad o situación” procurando una regulación bastante más correcta técnicamente que la laboral.

\section{Buenas prácticas para prevenir el acoso sexual o} por razón de sexo

En primer término conviene referirse a las conductas constitutivas de acoso sexual o por razón de sexo, pues habitualmente en los manuales y guías analizadas se diferencia entre tres actividades diferentes: el chantaje sexual, siendo el chantajista una persona jerárquicamente superior a la víctima que condiciona, de una manera directa o indirecta, alguna decisión laboral (acceso al empleo, permanencia, mejora de condiciones laborales...) a la aceptación de la propuesta (chantaje) sexual; en segundo lugar, el acoso ambiental, tratándose de un comportamiento de naturaleza sexual, de cualquier tipo, que tiene como consecuencia producir un contexto intimidatorio, hostil, ofensivo y humillante, pudiendo ser el acosador de superior o igual categoría profesional que la víctima, ${ }^{87} \mathrm{y}$ adicionalmente algunas guías incluyen el acoso sexual, en la redacción dada a este delito en el Código Penal, tratándose más bien de un tipo penal independiente que puede o no presentarse junto a los ilícitos laborales descritos. También se diferencia entre el "acoso técnico", siendo el padecido en el último año por una trabajadora en cualquiera de las situaciones definidas como acoso sexual, independientemente de que ella lo considere o no acoso sexual, y el "acoso declarado" o situaciones sufridas por una trabajadora en el último año y que ella considera como acoso sexual. ${ }^{88}$

Por lo que atañe al diseño específico de los protocolos contra el acoso, se deja al criterio de los agentes negociadores en la medida en que representantes de los trabajadores y empresarios deben llegar a un acuerdo sobre las fases y el contenido del protocolo que más se adapte a las características del ámbito laboral con-

87 Aclarando algunas dudas sobre planes de igualdad, cit., pág. 98 Concretamente las conductas pueden materializarse como "contacto físico deliberado y no solicitado, o un acercamiento físico excesivo e innecesario; comentarios o gestos repetidos de carácter sexual; llamadas telefónicas, cartas o mensajes de carácter sexual ofensivo; la persecución reiterada y ofensiva contra la integridad sexual; a exposición o exhibición de gráficos o imágenes de contenido sexualmente explícito, no consentidas y que afecten a la integridad e indemnidad sexual; bromas o proposiciones sexualmente explícitas que afecten a la integridad e indemnidad sexual; preguntas o insinuaciones acerca de la vida privada de la persona, que afecten a su integridad e indemnidad sexual; peticiones de favores sexuales, incluidos los que asocien esos favores con la mejora de las condiciones de trabajo del trabajador(a) o su estabilidad en el empleo; cualquier otro comportamiento que tenga como causa o como objetivo la discriminación, el abuso, la vejación o la humillación de un trabajador por razón de su sexo", págs. 99-100. Definición de los dos tipos de conducta pacífica entre la doctrina: Pérez del Río, T. La violencia de género en el ámbito laboral: el acoso sexual y el acoso sexista, Op. cit., pág. 22.

$88 \mathrm{El}$ acoso sexual a las mujeres en el ámbito laboral, cit., pág. 9. 
creto; sin embargo, conviene especificar cuatro criterios básicos recomendables para cualquier sistema de resolución de este tipo: una declaración de principios o criterios en los que se determinen los derechos y las obligaciones de las partes en el procedimiento; el sistema de denuncia de la presunta conducta en el que se respete la confidencialidad de la información; las sanciones disciplinarias previstas en caso de confirmación del acoso junto a la protección contra las posibles represalias del denunciante, $\mathrm{y}$ finalmente, una estrategia de formación y comunicación para prevenir futuras conductas similares. Los aspectos claves de los protocolos contra el acoso sexista suelen determinar la forma de presentar la denuncia y ante qué órgano, un procedimiento de tramitación y las medidas preventivas para atajar el hostigamiento provisionalmente. Respecto al órgano diseñado para intervenir, hay pluralidad de opciones: desde establecer órganos de carácter unipersonal pudiendo ser un agente de igualdad, o bien un órgano colegiado cuya composición puede ser variada. En otros supuestos los protocolos contra el acoso determinan que la denuncia puede presentarse ante cualquier responsable de la dirección de la empresa, de recursos humanos o de la representación legal de los trabajadores. ${ }^{89}$ Seguidamente se debe dar audiencia a los sujetos involucrados: víctima, presunto acosador y testigos, existiendo la posibilidad de facilitar el cambio de puesto de trabajo cautelarmente a la víctima, si bien son escasos los protocolos que incluyen medidas cautelares para que el presunto acoso cese automáticamente una vez que es puesto en conocimiento del órgano competente. ${ }^{90}$ En general, los procedimientos para solventar los supuestos de acoso suelen contener una fase previa de carácter informal tendiente a disuadir al acosador, y un procedimiento formal reservado a supuestos en los que los intentos de solucionar el acoso en un primer término no son efectivos o se trata de conductas especialmente graves (fases recomendadas en el Código de Conducta Comunitario para la protección de la dignidad de hombres y mujeres en el trabajo, de 1992.. ${ }^{1}$

Una vez demostrada fehacientemente la veracidad de la conducta acosadora, los convenios colectivos que incluyen protocolos contra el acoso establecen, en oca-

89 En: J.M. Serrano García. La obligatoriedad de los convenios de proteger la dignidad de la mujer y el hombre en el trabajo. Op. cit., pág. 281.

90 R.F. Gallaro Moya. Los nuevos planes de igualdad en la empresa: un análisis de las primeras experiencias. RDS, No 48, 2009, pág. 104.

91 Diario Oficial L 49 del 24.2.1992. Un procedimiento diferente, sin una fase previa tendente a resolver el acoso mediante su visualización en: G.M Sobrino González. Op. cit., pág. 63. siones, que si el acoso se ha producido sirviéndose de la situación jerárquica respecto a la persona afectada, la sanción disciplinaria se aplicará en su grado máximo, ${ }^{92}$ si bien el hostigamiento sexual o por razón de sexo constituye una falta laboral muy grave que puede motivar el despido. En la práctica se recomienda establecer en el protocolo como agravantes que la persona denunciada sea reincidente en la comisión de actos de acoso, que existan dos o más víctimas, si se demuestran conductas intimidatorias o represalias por parte de la persona agresora, que la persona agresora tenga poder de decisión sobre la relación laboral de la víctima, que la víctima sufra algún tipo de discapacidad física o mental, el estado psicológico o físico de la víctima haya sufrido graves alteraciones, médicamente acreditativas, que el contrato de la víctima sea o no indefinido, o que su relación con la empresa no tenga carácter laboral, que el acoso se produzca durante un proceso de selección de personal, que se ejerzan presiones o coacciones sobre la víctima, testigos o personas de su entorno laboral o familiar con el objeto de evitar o entorpecer el buen fin de la investigación, y finalmente, que la situación de acoso se produzca durante el periodo de prueba, e incluso con contrato de beca o en prácticas de la víctima. ${ }^{93}$ En cuanto al catálogo de sanciones laborales que pueden establecerse en los protocolos contra el acoso sexual laboral, encontramos desde la suspensión de empleo y sueldo, hasta la pérdida de la categoría profesional, pasando a ocupar una inferior, o el traslado forzoso del autor, dependiendo de la gravedad y circunstancias del ilícito laboral. ${ }^{94}$

Por lo que respecta a las medidas correctoras y preventivas concretas propuestas en las guías y manuales prácticos, a continuación enunciamos algunas de ellas: se recomienda elaborar un Código de Conducta que defina, prevenga y establezca sanciones en los casos en que se produzca algún caso de acoso sexual o acoso laboral por razón de sexo; designar a una persona como agente de igualdad para canalizar los casos de acoso sexual que existen en la empresa; incluir principios claros en el Convenio Colectivo, en los Estatutos Sociales y el Reglamento de Régimen Interno sobre situaciones de acoso sexual y laboral; realizar campañas de sensibilización a toda la plantilla para la identificación, prevención y denuncia de los casos de acoso sexual o acoso laboral por razón de sexo; realizar cam-

\footnotetext{
92 J.M. Serrano García. Op. cit., págs. 138-139.

93 Aclarando algunas dudas sobre planes de igualdad, cit., pág. 110.

94 G.M. Sobrino González. Op. cit., págs. 61-62.
} 
pañas de sensibilización animando a las mujeres trabajadoras víctimas de violencia de género a denunciar estas conductas; incluir entre la documentación que se facilite a la plantilla en el momento de su incorporación a la empresa (junto a la copia del contrato laboral), el protocolo de actuación de la empresa ante situaciones de violencia de género; facilitar a las trabajadoras que estén en esta situación fórmulas de flexibilización del tiempo y lugar de trabajo, tales como optar a una jornada flexible o a la movilidad geográfica o funcional; promover lugares de trabajo en los que las relaciones se desarrollen de igual a igual, limitando las relaciones desmedidas de poder; informar de comportamientos y comentarios sexistas, homófonos o irrespetuosos hacia la dignidad y libertad de las personas. ${ }^{95}$ Algunas de estas propuestas pueden perder efectividad por su imprecisión, siendo en estos casos imprescindible un compromiso real de la dirección de la empresa en el cumplimiento de los objetivos en la materia; precisamente, las medidas destinadas a evitar el acoso ambiental deben concretarse convenientemente al tratarse de conductas especialmente difíciles de erradicar al presentarse por lo general de manera intermitente y entre círculos privados y limitados de trabajadores. Por ello es importante garantizar un clima laboral no sexista, por ejemplo mediante el establecimiento de "un equipo de mujeres y hombres a través de la representación sindical de la empresa para facilitar la denuncia".96

Otras medidas proponen publicar el protocolo en la intranet de la empresa, así como publicitarlo en todos los medios de comunicación de que se dispongan en esta, el desarrollo de campañas de sensibilización, y queremos destacar la necesidad de proporcionar formación específica sobre el acoso sexual y el acoso por razón de sexo a toda la plantilla, incidiendo especialmente en los colectivos en los que por su organigrama o por antecedentes, son susceptibles de acoso, siendo esta política empresarial de visualización extremadamente importante y afortunadamente implementada en la práctica en algunos supuestos ${ }^{97}$ ejerciendo además, una función de prevención imprescindible en la materia.

95 Manual para la implantación de Planes de Igualdad en las Empresas de Economía Social, cit., págs. 73-74.

96 Planes de igualdad en el sector agroalimentario, cit., pág. 21.

97 Medidas propuestas en: Aclarando algunas dudas sobre planes de igualdad, cit., págs. 101-102; un ejemplo en el Plan de Igualdad de Vossloh España, S.A. (2009-2012), en el que se establece como objetivo la "formación específica a mandos y responsables que les permita identificar los factores que contribuyen para que no se produzca acoso y a familiarizarse con sus responsabilidades en esta materia”. C. Bravo \& R

\section{REFERENCIAS}

A. Álvarez Montero. Prevención de riesgos laborales con perspectiva de género. Gestión práctica de Planes de Igualdad, cit., págs. 118 y ss.

A. Bomarzo. Los planes de igualdad como obligación empresarial, 2009, pág. 55.

A. Martín Valverde, F. Rodríguez-Sañudo Gutiérrez \& J. García Murcia. Derecho del trabajo, págs. 796-797, Tecnos, Madrid, 2011.

A. Peláez Narváez. Planes de igualdad para entidades de la discapacidad del tercer sector, Cermi, Madrid, 2010.

A. Vilches Arribas, T. Pérez del Río \& M. Hernández Canosa. Guía de criterios y cláusulas para el tratamiento del acoso sexual y moral por razón de género en la negociación colectiva. Dirección General de la Mujer, Madrid, 2004, pág. 26.

A.M. Olmo Gascón. Igualdad por razón de sexo. Diccionario Internacional de Derecho del Trabajo. Valencia, TLB (en prensa).

A.M. Olmo Gascón. La tutela frente al acoso sexista en el trabajo. Violencia contra las mujeres. Un enfoque jurídico. Septem Ediciones, Oviedo, 2011, págs. 205-208.

AA.vv. Crisis y discriminación salarial de género. Secretaría Confederal dela Mujer ccoo, pág. 18. Madrid, 2012.http:// www.ccoo.es/comunes/recursos/1/pub85343_Crisis_y_ discriminacion_salarial_de_genero.pdf (09.01.2013)

AA.Vv. Diagnóstico de la igualdad de género en el medio rural. Ministerio de Medio Ambiente y Medio Rural y Marino, Centro de Publicaciones, Madrid, 2011.

AA.Vv. Los planes de igualdad entre mujeres y hombres en la negociación colectiva. Instituto de la Mujer, Ministerio de Igualdad, Madrid, 2009.

AA.Vv. Negociando la igualdad en las empresas: estado de la cuestión y estrategias para la implementación de una política de igualdad de género, Molina Hermosilla, O. (Dir.), Comares, Granada, 2012.

Asociación Global e-Quality, Unidad de Igualdad de Género, Instituto de la Mujer de Castilla-La Mancha. Guía práctica para la incorporación del "mainstreaming" de género: ¿cómo aplicar el enfoque de género en las políticas públicas? Toledo, 2009.

C. Bravo \& R. Gómez. Buenas prácticas en la negociación de los planes de igualdad. Secretaría Confederal de la Mujer Ccoo, Madrid, 2010, pág. 25. http://www.ccoo. es/comunes/recursos/1/699885-Guia_Buenas_practicas_en_la_negociacion_de_los_planes_de_igualdad. pdf (09.01.2013).

Gómez. Op. cit., pág. 52. 
C. Sáez Lara. Mujeres y mercado de trabajo: las discriminaciones directas e indirectas. Consejo Económico y Social, Madrid, 1994.

C.L. Alfonso Mellado \& G. Fabregat Monfortg. Los planes de igualdad en la administración pública. pág. 65, Bomarzo, Albacete, 2007.

C.L. Alfonso Mellado. Igualdad entre mujeres y hombres en la función pública. Albacete, Bomarzo, 2007, pág. 55.

Cámara Oficial de Comercio e Industria de Madrid. Guía para la implantación de un plan de igualdad en las pymes al amparo de la nueva ley de igualdad 2007. pág. 17, 2007. http://www.rse.camaramadrid.es/ficheros/Guial.pdf (09.01.2013).

Elkar-Ikertegia, S.Coop.And. Guía para la implantación de medidas de igualdad en las Cooperativas. Dirección General de Economía Social del Gobierno Vasco, 2008; Confederación Española de Cooperativas de Trabajo Asociado. Guía para la elaboración de planes de igualdad en cooperativas de trabajo asociado, 2008.

Emakunde/Instituto Vasco de la Mujer. Guía para un proceso de selección no discriminatorio. 2004.

Federación Agroalimentaria, Secretaría Mujer e Internacional ccoo. Planes de igualdad en el sector agroalimentario, pág. 18, 2009. http://www.agroalimentaria.ccoo. es/comunes/recursos/21/doc22801_Planes_de_Igualdad_en_las_empresas_del_sector_agroalimentario.pdf (09.01.2013).

Federación de Mujeres Progresistas-Plataforma de ONG de Acción Social. Guía para la elaboración de un plan de igualdad en ONG de acción social. Madrid, Plataforma de ONG de Acción Social, 2010.

Federación de Servicios a la Ciudadanía de ccoo. Aclarando algunas dudas sobre planes de igualdad. págs. 43-47, Madrid, 2011. http://www.fsc.ccoo.es/comunes/recursos/15621/doc69851_Aclarando_algunas_dudas_sobre_planes_de_igualdad.pdf (09.01.2013).

Federación de Servicios Públicos de UGT de Madrid. Manual para elaborar un plan de igualdad en la empresa. http:// www.fspmadridugt.org/dependencia/documentacion/ Guias\%20y\%20manuales/Manual\%20para\%20elaborar\%20un\%20Plan\%20de\%20Igualdad\%20en \%20 la\%20empresa.pdf (09.01.2013).

Federación empresarial de mujeres para la economía social de Andalucía, Instituto Andaluz de la Mujer, Consejería para la Igualdad y Bienestar Social. Manual para la implantación de Planes de igualdad en las Empresas de Economía Social, 2009, pág. 17. http://www.juntadeandalucia.es/empleo/calidad/admin/downloads/ descargar.php?id=428 (09.01.2013) http://plataformaisonomia.uji.es/emprendedona/wp-content/uploads/ igualdadeconomiasocial.pdf (09.01.2013).
Federación Española de Municipios y Provincias, Secretaría General de Políticas de Igualdad, Instituto de la Mujer, Ministerio de Trabajo y Asuntos Sociales. Guía para elaborar Planes Locales de Igualdad. (2005). http:// www.femp.es/files/566-182-archivo/Guia\%20elaboracion\%20Planes\%20Locales\%20Igualdad.pdf (26 noviembre, 2013).

Federación Española de Municipios y Provincias, Secretaría General de Políticas de Igualdad, Instituto de la Mujer, Ministerio de Trabajo y Asuntos Sociales, Guía para elaborar Planes Locales de Igualdad. 2005.

Fundación Mujeres, Instituto de la Mujer. Orientaciones para negociar medidas y planes de igualdad de oportunidades entre mujeres y hombres en las empresas: guías, 2008.

Fundación Mujeres, Ministerio de Trabajo y Asuntos Sociales, Instituto de la Mujer, Guía de buenas prácticas para conciliar la vida familiar y profesional. 2010, pág. 11. http://www.ib.ccoo.es/comunes/recursos/12/doc22183_Conciliacion_de_la_vida_laboral,_ familiar_y_personal._.pdf (09.01.2013)

Fundación Mujeres-Junta de Extremadura. Buenas prácticas para integrar la igualdad de género en las empresas, 2006, pág. 39. http://www.fundacionmujeres.es/img/ Document/15025/documento.pdf (09.01.2013)

G. Fabregat Monfort. La discriminación de género en el acceso al mercado de trabajo. La posibilidad de una nueva tutela a la luz de la Ley Orgánica 3/2007, del 22 de marzo, para la igualdad efectiva de mujeres y hombres. TLB, Valencia, 2008.

G. Fabregat Monfort. La negociación de los planes de igualdad en los convenios colectivos de ámbito sectorial. Negociando la igualdad en las empresas: estado de la cuestión y estrategias para la implementación de una política de igualdad de género. Molina Hermosilla, O. (Dir.), Comares, Granada, 2012. pág. 83.

G. Fabregat Monfort. La obligación empresarial de tutela frente al acoso laboral en la empresa. pág. 112, Bomarzo, Albacete, 2011.

G.M. Sobrino González. El acoso sexual y el acoso por razón de sexo. Análisis de medidas y planes de igualdad en la negociación colectiva. pág. 57, Observatorio de Medidas y Planes de Igualdad en la Negociación Colectiva, Comisión Ejecutiva Confederal de UGT, 2011. http:// www.ugt.es/Mujer/LIBROPLANESDEIGUALDAD_ UGT.pdf (09.01.2013).

Instituto de la Mujer, Ministerio de Trabajo y Asuntos Sociales. Guía práctica para diagnosticar la igualdad de oportunidades entre mujeres y hombres en las empresas. Madrid, 2002. http://www.fundacionmujeres.es/ img/Document/15024/documento.pdf (09.01.2013) 
Instituto dela Mujer, Ministerio de Trabajoy Asuntos Sociales. El acoso sexual a las mujeres en el ámbito laboral. http:// webs.uvigo.es/pmayobre/textos/varios/1informe_acoso_sexual.pdf (09.01.2013).

J. Cabeza Pereiro. Discriminación salarial indirecta por razón de sexo [Comentario a la TC S 58/1994, del 28 de febrero (вов del 24 de marzo)]. RL, No 2, 1994. Diferencias de trato reguladas en el art. 6 LOI y art. 17.1 ET.

J.C. García Quiñones. La formación profesional, los sistemas de promoción y los sistemas de clasificación profesional. Análisis de medidas y planes de igualdad en la negociación colectiva. Observatorio de Medidas y Planes de Igualdad en la Negociación Colectiva, Comisión Ejecutiva Confederal de UgT, 2011. pág. 133.

J.M. Serrano García. La obligatoriedad de los convenios de proteger la dignidad de la mujer y el hombre en el trabajo. La conciliación de la vida laboral, familiar y personal en la negociación colectiva de Castilla-La Mancha, AA.vv. Bomarzo, Albacete, 2009, pág. 276.

J.M. Serrano García. Participación y planes de igualdad en la Ley Orgánica de Igualdad efectiva entre mujeres y hombres, Albacete, Bomarzo, 2007, págs. 110-111.

J.F. Lousada Arochena. Acoso sexual y acoso sexista. El principio de igualdad en la negociación colectiva. AA.Vv., Lousada Arochena, J.F. (Coord.), pág. 364.

M. Elosegui Itxaso. Educar en la corresponsabilidad entre mujeres y hombres: la igualdad necesaria. Revista General de Derecho Canónico y Derecho Eclesiástico del Estado, No 20, 2009.

M. Elosegui Itxaso. La Ley Orgánica de igualdad efectiva entre mujeres y hombres: las acciones positivas para la igualdad laboral entre mujeres y hombres. Aequalitas: Revista jurídica de igualdad de oportunidades entre mujeres y hombres, No 20, 2007, págs. 11 y ss.

M. Vittoria Ballestrero. Igualdad y acción positiva. Problemas $y$ argumentos de una discusión infinita. DoxA, Cuadernos de Filosofía del Derecho, № 29, 2006.

M.A. Ballester Pastor. De cómo la reforma operada por el $R D$ Ley 3/2012 ha degradado el derecho fundamental a la conciliación de responsabilidades. RDs, No 57, 2012, pág. 108.

M.J. Dilla Catala. La clasificación profesional y la retribución salarial. Análisis de medidas y planes de igualdad en la negociación colectiva. pág. 35, Observatorio de Medidas y Planes de Igualdad en la Negociación Colectiva, Comisión Ejecutiva Confederal de UGT, 2011. http:// www.ugt.es/Mujer/LIBROPLANESDEIGUALDAD_ UGT.pdf (09.01.2013).

M.J. Morales Caparrós, M.J. Luna Jiménez \& A.I. Esteban Pagola. Diagnóstico de paridad en la universidad. Análisis a través de indicadores. Revista de Universidad y Sociedad del Conocimiento, vol. 7, No 2. 2010.
M.L. Molero Marañón. La conciliación laboral. Análisis de medidas y planes de igualdad en la negociación colectiva, cit., págs. 139-141.

M.T. Pérez del Río. Principio de no discriminación y acción positiva. Comentario a la Parte III del Plan de Igualdad de Oportunidad para la Mujer 1988-1990. Documentación Laboral, № 25, págs. 55-98, 1988.

Ministerio de Trabajo y Asuntos Sociales, Instituto de la Mujer Guía para una selección de personal no sexista.

Ministerio de Trabajo y Asuntos Sociales, Secretaría General de Políticas de Igualdad, Instituto de la Mujer. Manual para elaborar un Plan de Igualdad en la empresa. Aspectos básicos, págs. 10 y ss. http://www.upm. es/sfs/Rectorado/Gerencia/Igualdad/Plan\%20de\%20 Igualdad/Manual\%20para\%20elaborar\%20un\%20 Plan\%20de\%20Igualdad\%20en\%20la\%20empresa.pdf (09.01.2013)

Mujer, Ministerio de Trabajo y Asuntos Sociales. El acoso sexual a las mujeres en el ámbito laboral. pág. 5.

O. Molina Hermosilla (ed.). Gestión práctica de Planes de Igualdad. Bomarzo, Albacete, 2009.

Plan de Igualdad de la empresa Compañía Española de Petróleos, S.A. (Cepsa), Resolución del 23 de agosto del 2011, de la Dirección General de Trabajo, por la que se registra y publica el Plan de Igualdad de Compañía Española de Petróleos, S.A. (воE 05.09.2011), pág. 96079.

R.F. Gallardo Moya. Los nuevos planes de igualdad en la empresa: un análisis de las primeras experiencias. RDs, No 48, 2009, pág. 104

Red Concilia, Área de Gobierno de Familia y Asuntos Sociales del Ayuntamiento de Madrid. Cuaderno de trabajo 3: Del discurso de la conciliación al discurso de la igualdad, 2009. http://www.madrid.es/UnidadesDescentralizadas/IgualdadDeOportunidades/Publicaciones/ CuadernosTrabajo/CUADERno_3.pdf (09.01.2013)

S. Ameratunga \& M. Kawar Directrices para incluir la perspectiva de género en las políticas de empleo. (Informe de políticas 5: "Calificaciones y empleabilidad"), Organización Internacional del Trabajo, Departamento de Políticas de Empleo, Ginebra, 2011, pág. 4. http://www. ilo.org/wcmsp5/groups/public/---ed_emp/documents/ instructionalmaterial/wcms_170457.pdf (09.01.2013)

Secretaría Confederal de la Mujer de ccoo. Guía sindical: el acoso sexual en el trabajo. $2^{\text {a }}$ ed., pág. 28, 2000. http://www.funiovi.org/c/document_library/get_file?uuid $=8294$ cf0 1 -da9a-4e60-ba5413715fblad78\&groupId=41671 (09.01.2013)

SecretaríadeIgualdaddeUGT-Madrid.Guíaparalaelaboración de planes de igualdad en las empresas, pág. 36. http://madrid.ugt.org/pdfs/Menu\%20Mujer/Gu\%C3\%ADa\%20 para $\% 201 \mathrm{a} \% 20$ elaboraci\%C3\%B3n\%20de $\% 20 \mathrm{Pla}$ - 
nes\%20de\%20Igualdad\%20en\%20las\%20Empresas/ plan_igualdad.pdf (09.01.2013).

T. Pérez del Río, F. Fernández López \& F. Del Rey Guanter. Discriminación e igualdad en la negociación colectiva. Colección Estudios № 36, Ministerio de Asuntos Sociales, Instituto de la Mujer, Madrid, 1993, pág. 263.
T. Pérez del Río. La violencia de género en el ámbito laboral: el acoso sexual y el acoso sexista, págs. 55 y ss, Bomarzo, Albacete, 2009. 